\title{
تصميم الملابس بمنهجيات علوم الطاقة
}

\author{
هاله عادل محمد منصور \\ جامعة حلوان - كليه الإقتصاد المنزلى مله مله \\ معيده بقسم الملابس والنسيج
}

محمد سمير الصاوى

إيمان عبد السلام عبد القادر

جامعة حلوان - كليه الإقتصاد المنزلى جامعة مصر الدوليه - كلية الهندسه قسم العمارة قسم الملابس والنسيج

\section{ملخص البحث}

يهدف البحث الى طرح وصياغة منهجا للتعامل بمقاييس وأسس علوم

الطاقة فى تصميم الملابس للتوصل إلى تصميمات تحقق الجانب الوظيفى والجمالى والنفسى، كما بهدف إلى إكمال حلقة تصميم الملابس بالتكامل بين عناصر وأسس التصميم وقواعد وأسس بعض علوم الطاقه مثل (علم الطاقه الصينى والهندى القديم وعلم هندسة التشكيل الحيوى "البايوجيومترى" وعلم هندسه الأعداد والنسب) فى تصميم منتج ملبسى للشباب يهدف لرفع كفاءة أداءهم

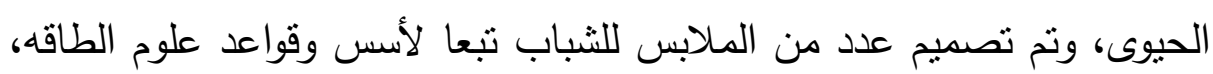

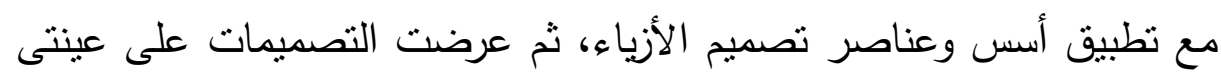
البحث التى تمثلت فى عدد (6) من المتخصصين فى تصميم الأزياء للتعرف على أرائهم فى تلك التصميمات ومدى تحقق فيهم النواحى الجماليه والوظيفيه من خلال اسنطلاع رأى، و (30) من الثباب لمعرفة ارائهم فى مدى مناسبة ولى فئية

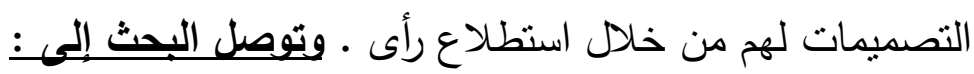

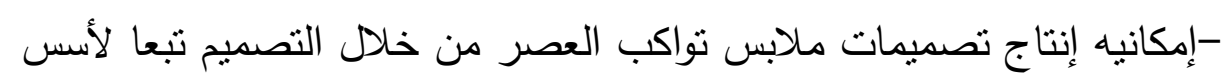
وقواعد علوم الطاقه مما قد يجعلها تحمل فى طياتها طاقه إيجابيه نساعد 
الإنسان على أداء الوظائف الحيويه بكفاءه،التصميمات المقترحه والتى نم

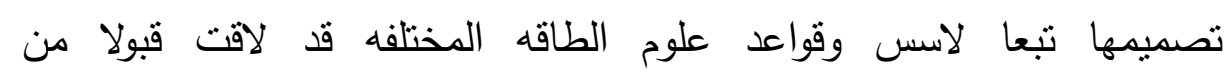
المتخصصين، وتوصل ان هناك تصميمات اجتمع عليها اراء اغلب المتخصصين انها تحمل قيم جماليه اكثر من غيرها فالتصميم الثالث كان أفضل

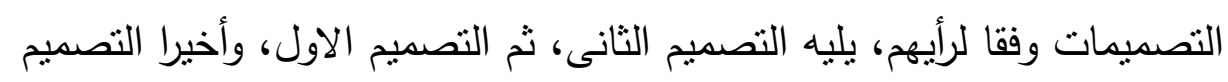

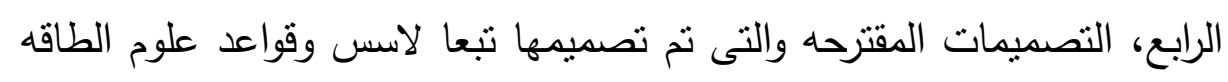
المختلفه قد لاقت قبولا من المستهكات .

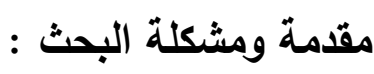

الملبس هو الجلد الثانى للإنسان والذى يحميه مما يتعرض له من مخاطر خارجيه لذلك يمكن اعتباره الدرع الواقى له، كما ان الملابس لها دور

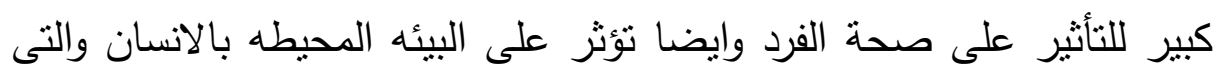

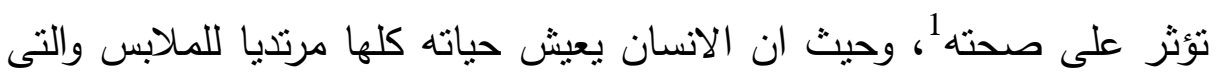
تعد اول طبقه من طبقات البيئه المحيطه به وباختلاف انواع الملابس وخامتها وتصميماتها يختلف تأثنرها على الانسان نفسيا وجسديا، هذا مادعى الانسان الى الى

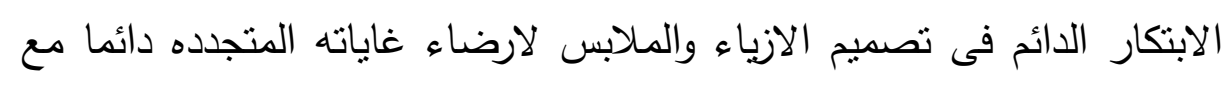
تطورات المجتمع والبيئه التى يعيش فيها ـ لإبـ

الآن ظهرت للإنسان بعض المشكلات التكنولوجية الحديثة منل التأثنرات

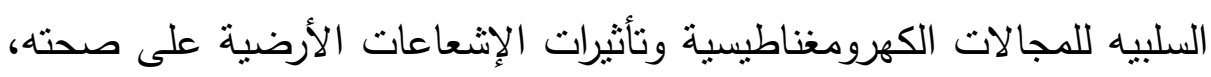
ومع نطور نظريات الفيزياء ظهرت مفاهيم جديدة للكون تقدم على أنه مزيج من الطاقه، وهذه المفاهيم الجديدة أدت إلى تغيير جذرى فى صياغة العلوم المختلفة،

$$
\begin{aligned}
& \text { 1 ) منال البكرى المتولى :"الملابس وصحة الانسان في القرن الحادى والعشرين" ، مجلة بحوث التربيه النوعيه ، العدد }
\end{aligned}
$$

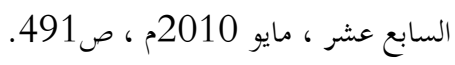


وشمل هذا التغيير المفاهيم الخاصة بكل المنتجات والأماكن والأشياء التى يتعامل معها الإنسان وبالتالى أصبح تعريف عناصر تشكيل وصياغة هذه الأشياء أنها عبارة عن كيانات مختلفة من الطاقة، حيث أن كل من (الثكل -

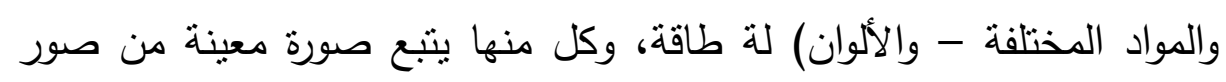
الطاقة التى تؤثر على المستخدم لها . وعلى هذا الأساس فإن صياغة التصميم لكل منتج يتعامل معه الإنسان أصبحت تتعدى بعدها النتكيلى المدرك إلى بعد جديد غير مدرك، وأصبحت هلئ وسيلة لصياغة وتتكيل نوعية الطاقة المحيطة به وبالتالى أصبحت أداة للنأثثر بدير على صحة الإنسان واتزانه الحيوى . والطاقة الحيوية (Bioenergy) هى التى تحكم العلاقة بين الأنظمة الحيوية للكائنات الحية، وتتتوع صورة هذه الطاقة داخل جسم الإنسان ما بين

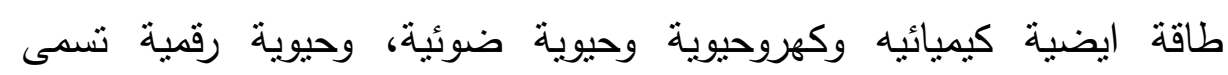
(مغناطيسية الحياة) ، وتعد تلك العلوم أحد الحلول المناسبة لإدخال التوازن فى وحئ وليه

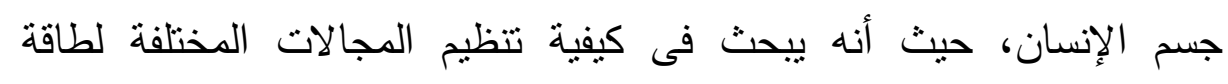
الكائنات الحية لتوفير الإنسجام التام فى الكون بين جميع مجالات الطاقة المختلفة، وهى علوم تدرس العلاقة بين ثلاث عناصر : (الثكل - الطاقة - الوظيفة)كما أنه يدخل العامل

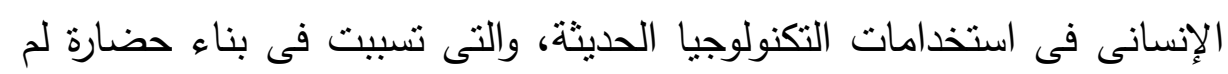
يسبق لها مثيل فى نوفير أساليب الراحة للإنسان ولكن على حساب صحة

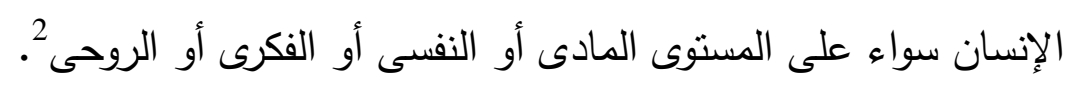


ومن هنا جاء الاهتمام بتلك العلوم التى تحقق التوازن النوعى فى الطاقة الحيوية والتوافق فى تبادل الطاقة مع البيئة المحيطة، وهو ما يشار إليه علميا بتوازن تبادل الطاقة البئى النوعى 3.

وقد أثبتت العديد من الدراسات فى مجالات مختلفة أن تطبيق علوم

الطاقة على المنتجات لها تأثثر إيجابى على بيئة الفرد المحيطة، وبالتالى تأثير

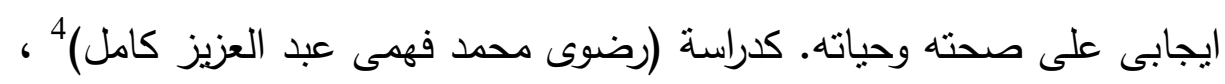
و (سالى الصاوى و باسل كمال ومحمد سمير)5 ودراسة(نيفين شرف ومحمد سمير الصاوى و اخرون )6 ،وأيضا دراسه (مها محمود إبراهيم)7، و (ريهام محسن محمد)" ، و (أميرة السيد كامل) فئ مجال تصميم وتتفيذ البيئات السكنية المختلفة كانت من أهم نتائج تلك الدراسات أن استخدام عناصر التشكيل الحيوى أدى إلى الحصول على مساكن صحية وأيضا استشفائية وتحسين العلاقة بين

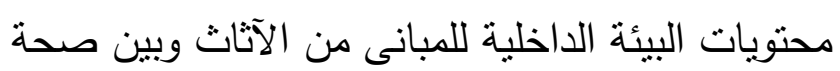
الإنسان، كما بوجد عدد من الدراسات القليلة فى مجال طباعة من الابن

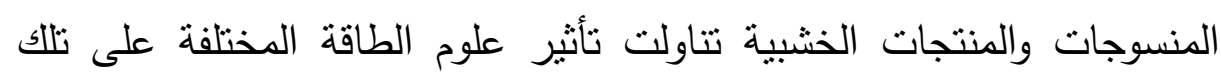

$$
\begin{aligned}
& \text { 3 ) سالى إسماعيل عراف :"صياغه مفردات لغه هندسه التشكيل الحيوى فن تصميم الأثاث وأثرها على معلالات }
\end{aligned}
$$

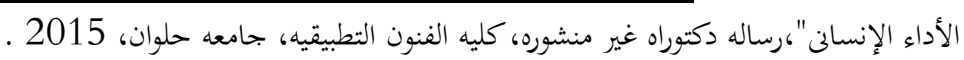

$\left.{ }^{4}\right)$ Radwa Mohamed Fahmy, (2015)Influence Of Biogeometry On Thermal comfort.

.GIZA, EGYPT-FACULTY OF ENGINEERING, CAIRO UNIVERSITY

5) Sally Essawy, Basil Kamel, Mohamed ElSawy, Timeless Buildinee And Human Brain The Effect of Spiritual Spaces on Human Brain Waves, International Journal of Architectural Research

6) Nevin E. Sharaf, Mohamed Samir El-Sawy and Other.(2014). Protective Role of Biogeometry Against Indoor Pollutants of Some Egyptian Building Materials in Adult Male Rats. Misr International University Cairo, Egypt.

7) مها محمود إبر اهيم :" صياغة جديدة لعناصر التصميم الداخلى من منظور علوم الطاقة "، رسالة دكتور اه،

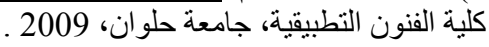

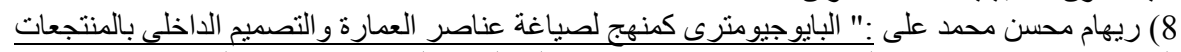

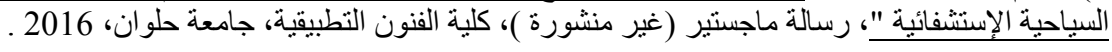

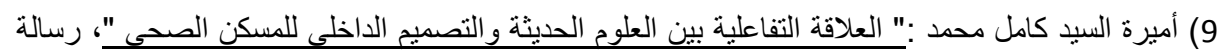
ماجتير( غير منشورة )، كلية الفنون التطبيقية، جامعة حلوان، 2017 ـ 
المنتجات كدراسه(سماح عبد العاطى)1010 ، وفى مجال تصميم الازياء تطرقت دراسة (آلاء أشرف)11 لعلاقة الملابس بالتشكيل الحيوى عن خلال "دراسة الاتجاهات الحديثة لتصميم الأزياء باستخدام هندسة التشكيل الحيوى" وتتاولت الدراسة تصميم منتجات مختلفة تبعا للنسب الخاصة بهندسة التتكيل الحيوي، لهياء والإقتباس من كل تصميم عدد من التصميمات تتبع الإتجاهات الحديثة للملابس

هذا مادعى الباحثين إلى فكرة البحث الحالى والتى تعتمد فى الأساس

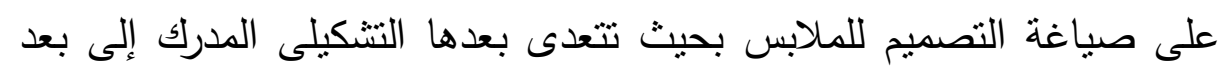

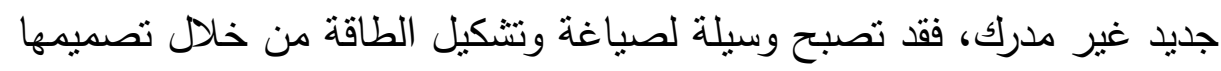

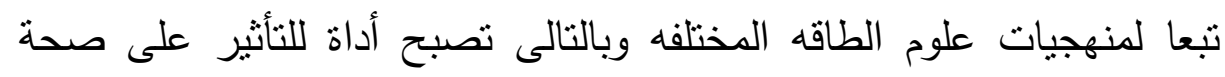
الإنسان وإتزانه الحيوى وتتكون أداة للحماية من الترددات والموجات الضارة

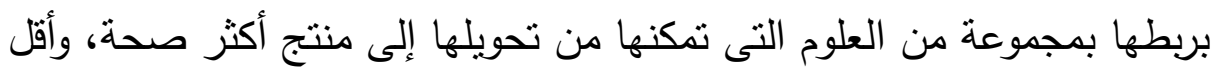
تلوثا من الموجات السالبة، وبالتالى مساعدة الإنسان على أداء وظائفه بالكفاءة المطلوبة من خلال زيادة الطاقة الحيوية له . ويمكن تحديا مشكلة البحث فى التالي : لهن

- ما مدى نجاح تطبيق منهجيات علوم الطاقة فى تصميم ملابس للفتيات فى

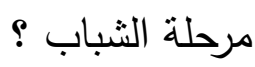
- ما هو رأي المتخصصين في التصميمات المقترحة من الناحيه الجمالية ؟ - ما درجة تقبل المستهلكين للتصميمات المقترحة؟

10) سماح عبد العاطى أحمد: مرجع سابق ذكرة: الأ 11) آلاء أثرف السيد: " اتجاهات حديثة لتصميم الأزياء باستخدام هندسة التثكيل الحيوى" رسالة ماجستير،

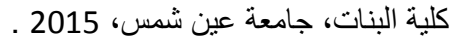




\section{ويهدف البحث الى:}

- - ابتكار تصميمات لفئة الثباب من الفتيات باستخدام بعض عناصر التصميم من خلال علوم الطاقه.

- - التعرف على رأى المتخصصين في التصميمات المقترحة من الناحيه

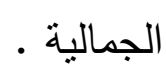

- قياس مدى درجة تقبل المستهلكين لتلك التصميمات .

\section{اهمية البحث : أبح}

قد يفيد هذا البحث في : له :

محاولة إيجاد علاقة بين تصميم الازياء وعلوم الطاقه مع تقديم صياغات جديدة للملابس نتيجه المزج بين عناصر التصميم وابجديات علوم الطاقه ـوالاستفادة من تأثير طاقة عناصر التصميم فى تصميم ملابس للثباب تعمل على نوازن لئن الطاقة الحيوبه في اجسامهم. فروض البحث :

1-يمكن الاستفادة من دراسة علوم الطاقه في ابتكار تصميمات تتاسب الفتيات في مرحلة الثباب.

2-توجد فروق ذات دلالة إحصائية بين التصميمات الاربعه وفقا لآراء

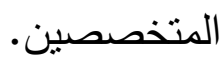
3-توجد فروق ذات دلالة إحصائية بين التصميمات الاربعه وفقا لآراء المستهلكات مصطلحات البحث : تصميم الملابس:

لغه فنيه قوامها مجموعه من العناصر المترابطه كالخط ، الثكل ، اللون والخامه بسماتها وحالتها من حيث الطاقه والمحكومه بعدد من الاسس كالسيطره 
والتوازن والايقاع وتوظيفها بما يتلائم مع جسم الانسان لتحقيق الجمال والمنفعه

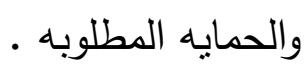

يعد تصميم الازياء من اهم الفنون الاساسيه في الحضاره فهو يعرض العديد من مظاهر ثقافات الماضي ويوضح الخصائص الذي تتصف بهن المجتمعات عبر القرون 12 علوم الطاقه :

هى العلوم التى تتاولت دراسة تلك الطاقة الكامنة المحركة لقوى الكون الطبيعية والتى تسير فى كل أنماط وصور الحياة ،واتزان هذه القوى يساعد على البقاء وانشطارها يدمر ماحوله واختلالها يؤثز سلبا على الحياة بصورة عامة. وعلوم الطاقة الحيويه هى تلك العلوم التى تدرس اثر المؤثرات الخارجيه والداخليه على العمليات الحيويه والطاقه الداخليه للكائنات الحيه كعلم (الطاقه الصينى والهندى القديم وعلم هندسة التشكيل الحيوى "البايوجيومترى" وعلم هندسه

$$
\text { الأعداد والنسب) }
$$

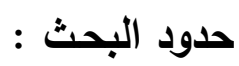

اقتصر هذا البحث على دراسة بعض علوم الطاقة كعم الطاقه الصينى والهندى القديم وعلم هندسة التشكيل الحيوى "البايوجيومترى" وعلم هندسه الأعداد والنسب و تطبيق أسس وقواعد هذه العلوم فى تصميمات لبلوزات للفتيات من

$$
\text { سن (18-30). }
$$

تمثلت عينة البحث فى مجموعتين :

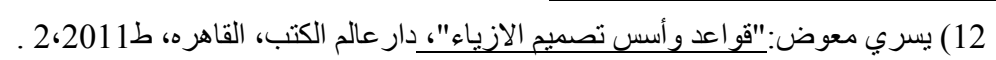

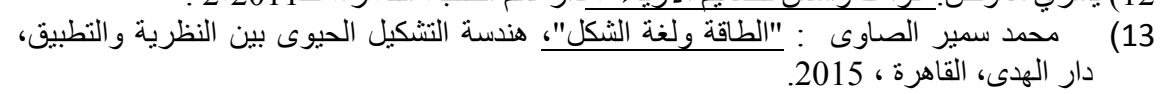


المجموعة الاولى : هى عدد من المتخصصين الاكاديمين فى مجال الملابس والنسيج وعددهم (10).

المجموعة الثانية : هى عدد من الفتايات وعددهم (100 ) ) . منهج البحث:

يتبع البحث المنهج الوصفي التحليلي والدراسه التطبيقيه.

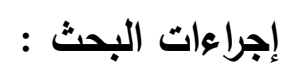

اولا :الاطار النظرى :

1 1-تصميم الازياء.

إن تصميم الأزياء فن من الفنون التشكيلية لما فيه من الإبداع وابتكار تصاميم جميلة ونافعة للإنسان فهو يجمع بين الإحتياجات الجمالية والنفعية والخاصة والعامة في نفس الوقت، وإن عملية بناء التصاميم تعتمد بشكل عام على الكثير من الدراية والدقة والمهارة وتفهم الأساسيات بالإضافة إلى القدرات

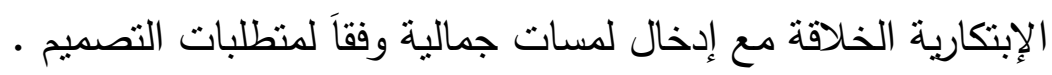
عناصر تصميم الأزياء. تعتبر الخطوط، بانواعها المختلفه والأشكال، والألوان بخصائصها المتعدده، والمواد(القماش) بتأثيراته الناتجه من نتوع سطحه وتراكيبه النسيجيه المختلفه هي العناصر المكونة لأي تصميم، والفكرة العامة في تصميم الأزياء

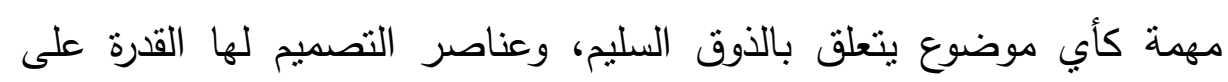

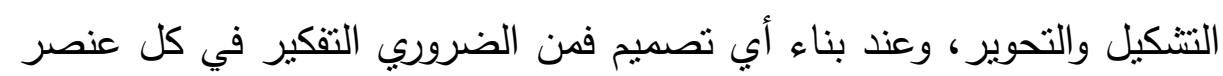

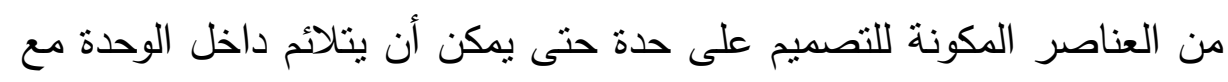
باقي العناصر، لأن جمال كل عنصر يتوقف على الصلة بينه وبين العناصر الأخرى حتى نصل إلى الصورة الفنية المبتكرة . 
وعناصر التصميم هي مفردات يستخدمها الفنان أو المصمم، وإدراكه لهذه العناصر إدراك جيداً واعياً بساعده في عملية التخطيط ويجعل عمله سهلاً طيعاً

$$
\text { 2-2 وهذه العناصر هى ( الخط - الثكل - اللون - الخامه) . }
$$

قامت الحضارات السابقة على علوم ومفاهيم تبنى أساسا على ملاحظة

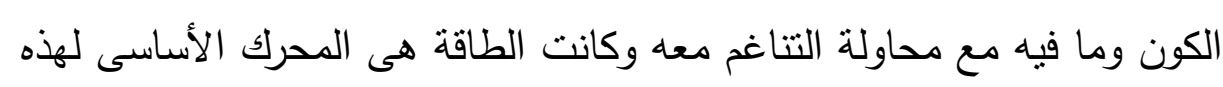
العلوم والتى منها علم الطاقه الصينية القديمة، الطاقه الهنديه القديمه، علم

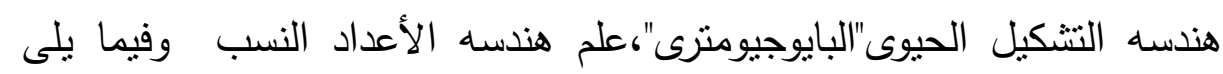
توضيح لكل علم من العلوم • أ-علم هندسه الطاقه الصينية القديمة : اتخذت الطاقة فى الحضارة الصينية القديمة اسماء منها "ثىى" وعبر عنها الصينيون بانها تتساب فى خطوط وقنوات تمتد عبر الكائن الحى وخاصة الانسان (الجسم البشرى ) وأن علاج المرض يكون بنتشيط انسياب هذه الطاقة

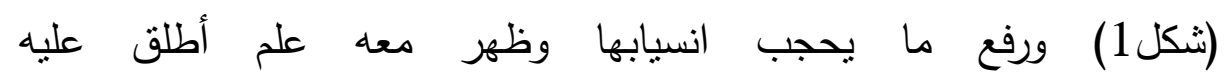

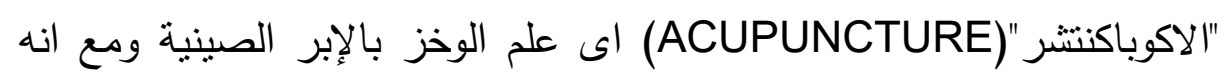
ظل يهاجم لفترة طويلة من مدارس الطب المختلفة إلا أنه الآن اعترف به كأحد الطرق الهامة لعلاج كثير من الأمراض والتى قد يفشل فيها الطب الحديث وكذلك وضعوا الخرائط لجسم الانسان ومراكز ونقط الطاقة ل14. 


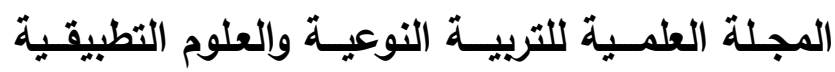

\section{The Scientific Journal of Specific Education and Applied Sciences}

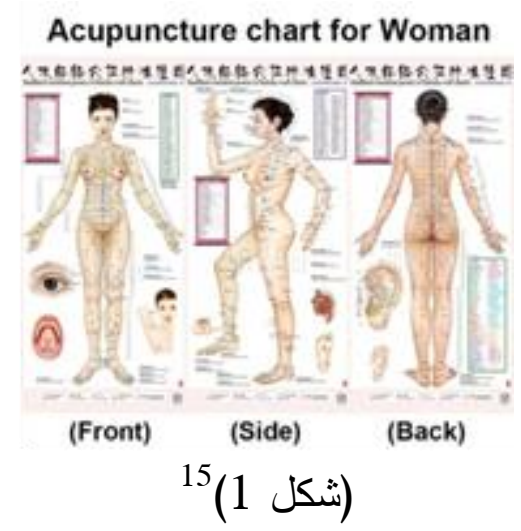

ويقوم هذا النظام بإمتصاص وتوزيع طاقة الحياة للخلايا والأنسجة والأعضاء وعرف العالم هذا النظام من خلال مسارات الطاقة المخنلفة بالجسم والتى يقوم عليها العلاج بالضغط والابر الصينية والذى أصبح معترفا به دوليا وطبيا وأصبح بدرس فى العديد من مدارس الطب. وهذه النقاط الخاصة تقع على مسارات الطاقة التى تحمل إحدى أنواع طاقة الحياة وهو "الثى" وهذا النوع الخاص من الطاقة ياتى من خلال ثيلاثية مصادر : أولها : ما باتى من الطاقة الحيوبة المورثة من الوالدين . ثانيها : هى جزء ممتص ومنتج من الأغذية التى تؤكل . ثالثها : وهو أهمهم والذى يأتى مباشرة من البيئة المحيطة ويأخذ مساره إلى داخل الجسم من خلال مسارات الطاقة الرقيقة وتقلها الى المسارات التى توزعها على جميع أعضاء الجسم وتبعا لنظربة الطب التقليدى الصينى فإن المرض هو نتيجة لعدم اتزان تذفق الطاقة "شي" الى الأعضاء المختلفة وأن العلاج بالضغط او بالابر الصينية هو أحد الطرق التى تساعد على إعادة هذا الاتزان 16.

15) Acupuncture chart for women https://ae01.alicdn.com/kf/HTB1xgk m6hSKjiSspn6A79XXaa.jpg? size $=194222 \&$ height $=800 \&$ width $=800 \&$ hash $=725$ af 40 699ce168b973762belee Acupuncture chart for women 
ب-علم هندسه الطاقه الهنديه القديمه:

وفى الحضارة الهندية ظهرت هذه الطاقة والتى كانوا يعتقدون أنها تسود المكان وتسنطيع شفاء المرضى وهى التى أطلقوا عليها "برانا" وهى "باللغة السنسكريتية" تعنى الطاقة الأولية وفى بعض الأحيان تترجم على أنها تتفس وفى لتهى

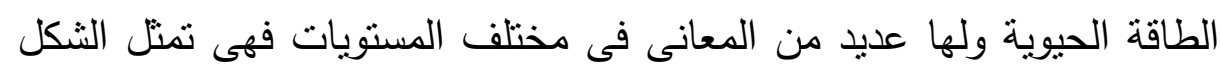
الأساسى للطاقة التى تعمل فى المستوى العقلى وكذلك فهى الطاقة الأولية الخلاقة والتى تتبع من قوى الطبيعة، والبرانا هى التى تقوم على إعادة صياغة

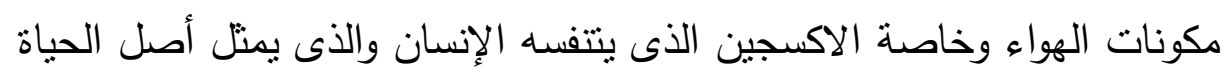
وترتفع البرانا داخل الفرغات المعمارية وتظل مثقاربة ومتلاحمة مع الفراغ مهما كان شكل الفراغ ولكنها ترتب بتوجيهه 17. ومن دراسة هذه الطاقة ظهرت علوم ذات صلة بها مثل دراسة قنوات لتهره

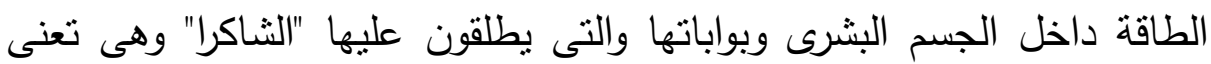
باللغه "السنسكريتية" - دوامات أشبه بالعجلات (شكل2) وكان الهنود يعتقدون أن الطاقة القادمة من العالم الأثيرى تتفذ الى الجسم البشرى من خلال هذه دئه

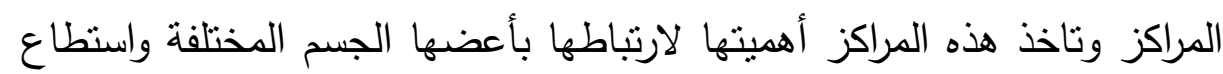
العلم الحديث تصوير هذه المراكز بإستخدام طريقة كيرليان 18.

David, Furlong. (2003).Working With Earth Energies.London:Judy Piatkus limited.

17)

18) Cox,Kathleen.(2000).Vastu Living Creating A Home For The Soul. New York: Marlowe and Company. 


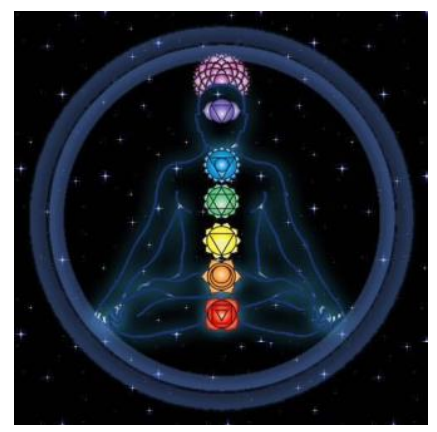

\section{9 (شكل 2)}

وهذه الطاقة هامة لصحة الإنسان ويمكن ان نرجع هذه الطاقة إلى "الطاقة الروحية " والتى تتطلق من خلال مداخل مختلفة بالجسم وترتبط هذه المداخل بالاعضاء المختلفة المادية وهو نظام خاص بالمراكز السبعة والتى بطلق عليها

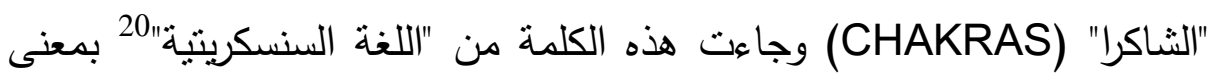
عجلة والتى بواسطة قدرات خاصة أمكن لبعض الناس رؤيتها واستطاعوا أن يصفوها بأنها مثل العجلات الدائرية الملوية من الضوء الملونه وأمكن الآن رؤيتها وتصويرها وقياسها بواسطة أجهزه القياس العملية التى تصور الهالة حيث تمنص الطاقة الكونية الرقيقة للجسم من خلال تلك المراكز وتتدفق هذه الطاقة بداخل الجسم ويطلق عليها "البرانا" بالغة الهندية وتتأثر تلك الطاقة

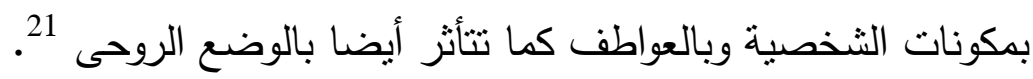

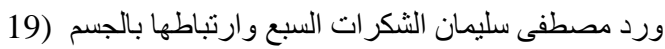

https://masterward1.blogspot.com/2016/03/blog-38.html_post,2016

20) www.esatclear.ie/cammalot/auraphotos.html

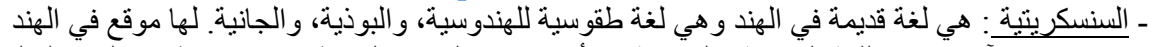

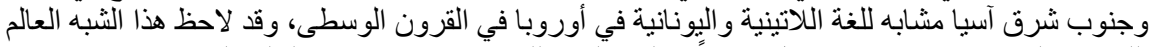

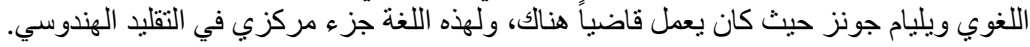
21) Alvino, Gloria : The Human Energy Field in Relation to Science, Consciousness, and Health, 1996 ,http://www.vxm.com . 
وأول هذه المراكز السبعة هو مركز الجذور والذى يقع فى نهاية العمود الفقرى الذى برتبط بالهيكل العظمى بالنخاع العظمى وهو المصدر الاساسى لتكوين هركز الخلايا ونتيجة لهذا الارتباط فيعتقد أن لها ناثير كبيرا فى تقوية جهاز المناعة . والمركز الثاني يقع مباشرة فوق الحوض السفلى وتقع عند النساء أعلى المبايض تلثن

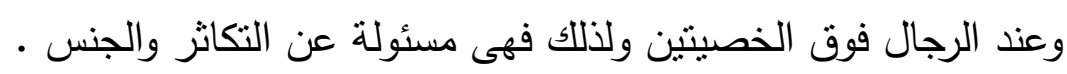
المركز الثالث يقع فوق المعدة ويرتبط بالبنكرياس والغدة الكظرية والتى ترتبط بعمليات الهضم وتتعلق أيضا بعمليات الإجهادات المختلفه بالجسم.

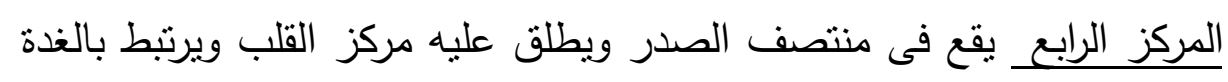
وهى التى تلعب دورا أساسيا فى تتظيم مستويات الدفاع داخل الجسم 22. والمركز الخامس يرتبط مباشرة بالغدة الدرقية ويقع مباشرة فوقها وهى ترتبط

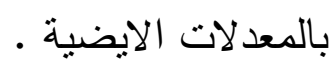

والمركز السادس أو مركز الجبهة ويقع ما بين العينين وترتبط مباشرة بالغدة النخامية وهى الغدة الأساسية المرتبطة بالمخ وهى تتتج هرمونات خاصة نرتبط بمعدلات الأداء والنشاط المختلفة المركز السابع أو المركز التاج وترتبط أيضا بالغدة النخامية وتؤثز فى إنتاج

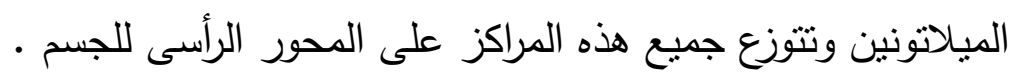

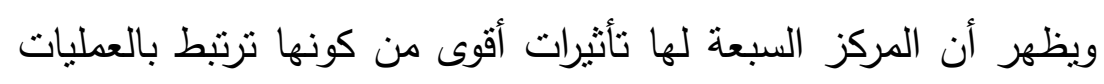

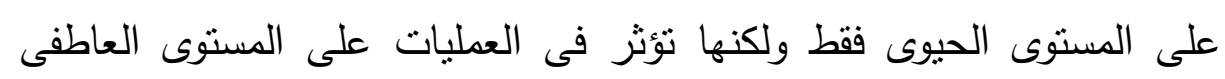
والروحى فكل شاكرا ترتبط بعصب خاص يعرف بالعقد العصبية وكل منها يعتبر

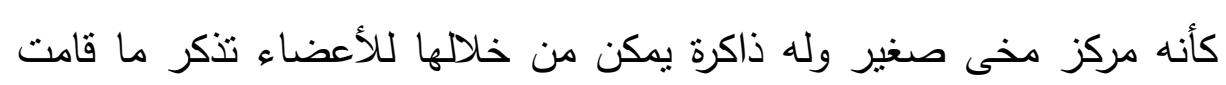

22) Lubeck,Walter.(2000). Aura Healing Handbook. Shangri-la,USA:Lotus Press. Gerber,Richard.(2000). Vibrational Medicine For the $21^{\text {st }}$ Century. London: Judy 23) Piatkus Ltd. 
ج- علم هندة التثكيل الحيوى (البايوجيومترى ): Biogeometry

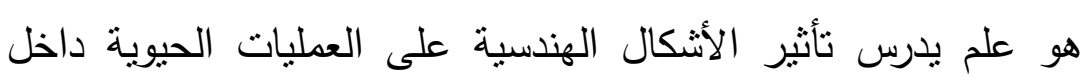
الكائنات الحيه224 ، ويبحث عن كيفية إيجاد طاقة نوعية متتاغمة في البيئة الئن

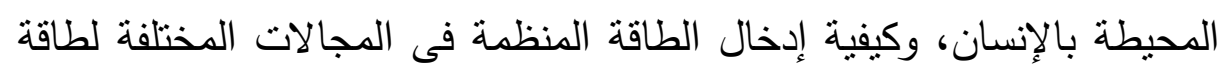

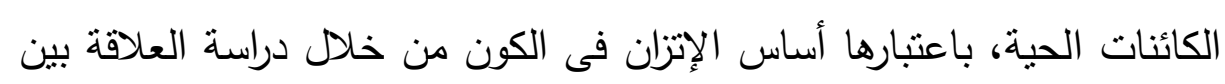

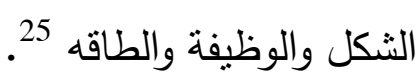

وعلم البايوجيومترى ينظر للكون على أنه محيط هائل من الذبذبات

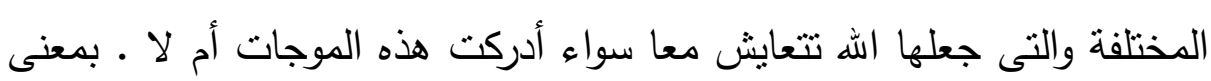

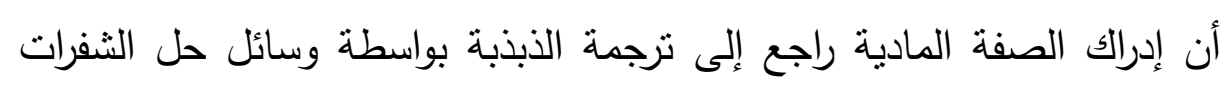

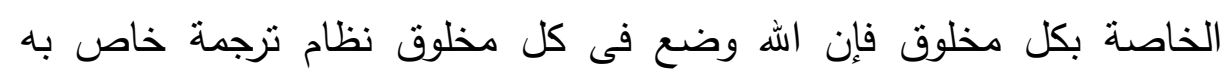

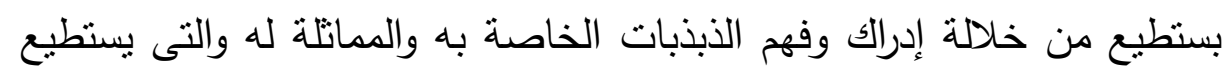

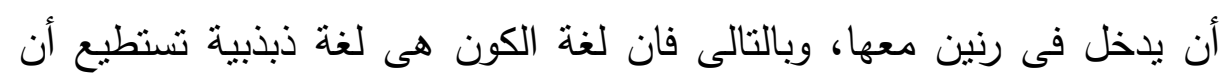

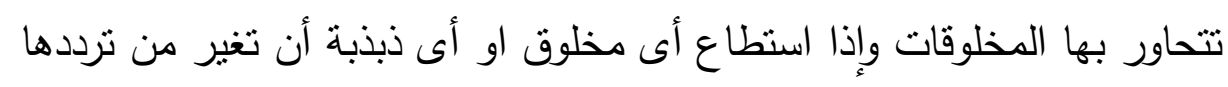

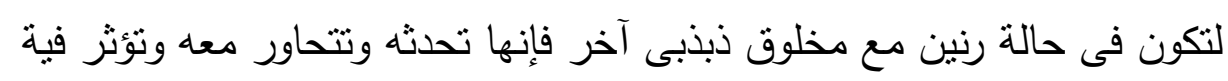

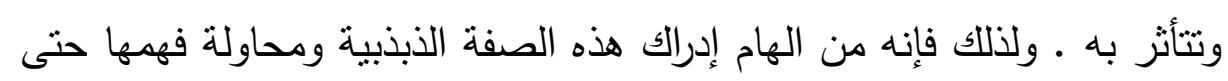

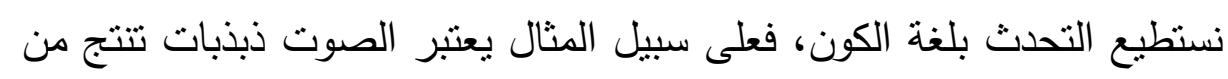

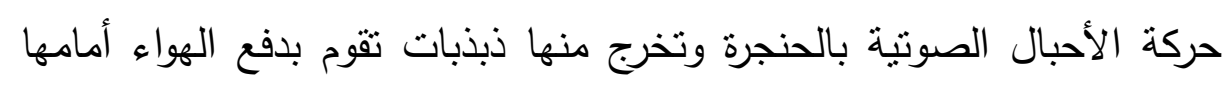

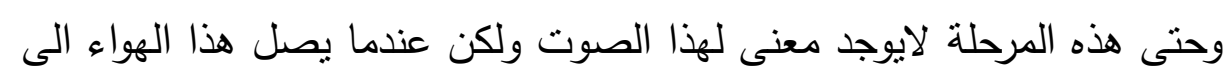

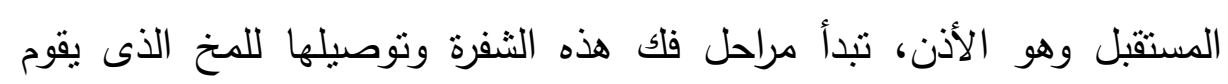

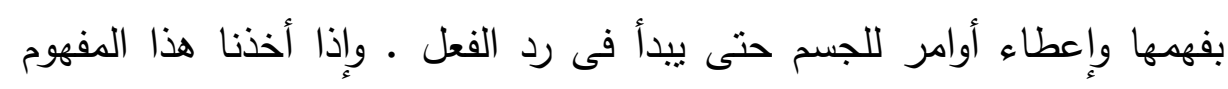

24)محمد سمير الصاوى :" العمارة و الهندسة الحيوية ، نحو منهجية لرفع كفاءة الأداء داخل الفر اغات المعمارية

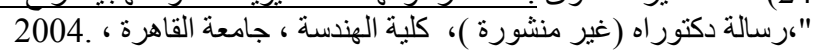
25)Ibrahem Karim : Back to Future for Mankind, Bio Geometry Consulting Ltd,Egypt,2009. 
وطبق على كل الكون نجد أنه لابد من وجود مرسل أو مصدر للابذبة ولابد من وجود مستقبل لها

وبما أن هذه الأشكال الهندسية لها ذبذبتها الخاصة فهى تؤئز بقدر ما فى المحيط الخاص بها وكل من يتعامل مع هذه الاشكال فهو بصورة او باخرى

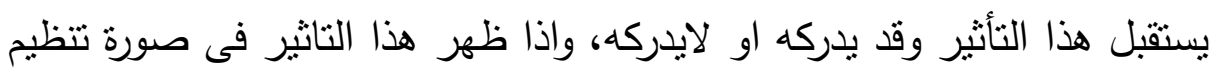
للطاقة ذبذبية ضارة وبالتالى فإن عملية البحث عن الاشكال التى يصدر عنها تلاك الموجات المنظمة هى بداية الفكر فى علم البيوجيومترى وبدراسة الاثكال الهندسية المختلفة وتركيباتها والعلوم المتصلة بها سواء أكانت مادية ام ردزية وجد أن هذه الطاقة المنظمة تتواجد بالمركز وان الثكل الهندى الذى لانه لايمكن رسمه بدون مركز هو الدائرة ، والدائرة كشكل هندسى يرمز لها فى الحضارات المختلفة على انها رمز الى الله فهو كل شئ فى المركز ولا شئ فى المحيط الخارجى، فهو الاول فى المركز وبلا نهاية فى المحيط والكون كله يعمل من لن منظومة دائرية تعتمد على المراكز فالمجرات بالسماء لها مركزها والذرة الدقيقة لها مركز ها وكلما وصل الانسان الى مركز وجد مركزا آخر أدق منه ولا نهاية لهذ المراكز إلا عند النقطة النهائية وهى الله 27.

\section{أسس التشكيل باستخدام البيوجيومترى}

فى علم البيوجيومترى يبدو أن هناك عدداً من هذه الأسس التشكيلية له له مردود فى مفهوم الطاقة المنظمة وذللك منل:الإيقاع والنسب والتوجبه والارتباط بالمركز والاتزان المتماثل وغير المتمانل والتداخل، وتعمل هذه العناصر منفردة

26) Karim,Ibrahim. (2002). Biogeometry and the Forming Process Back to the Future of New Architecture. Alexandria:First International Conference of the UIA-WPAHR$\mathrm{V}$ on Architec-ture\&Heritage as a Paradigm for Knowledge and Development Lessons of the Past, New Invventions and Future Challenges.

27) Karim,Ibrahim : Op cit. 
أو مجتمعة على إيجاد نوعية من الطاقة اللطيفة المنظمة داخل النشكيل وهذه الطاقة تؤثز إيجابياً على محتوى هذا التشكيل وذلك مما يضيف بعداً جديداً

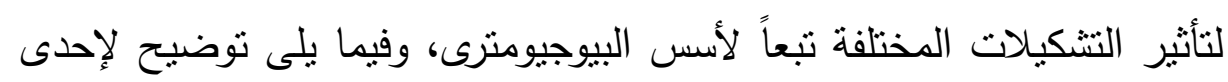
أسس التشكيل وهو : أسن

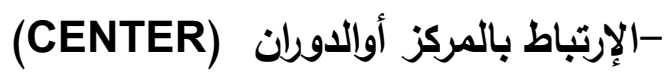

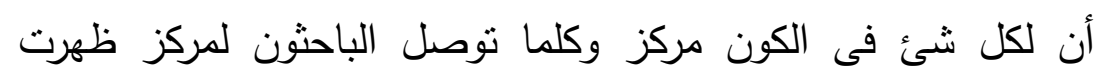
تفاصيل ومراكز أدق أى أن منظومة الكون مبنية على وجود مركز واحد وهو الله ومنه تشع كل المحاور الأخرى والتى بدورها تحتوى على مراكز ولتتبع هذا

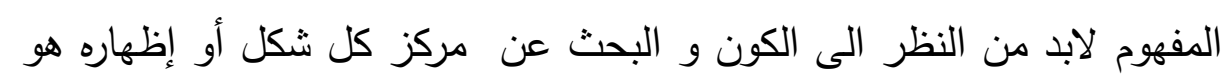
إظهار لطاقة هذا النتكيل فدوران المربع حول مركزه لإيجاد شكل النجمة يوجد

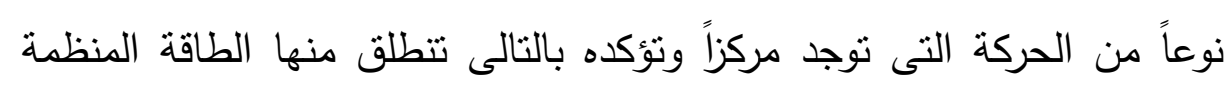

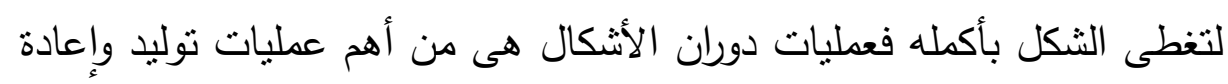
تتشيط طاقة الثكل بايجاد مركز حقيقى به وقد لوحظ من قياسات الطاقة المنظمة أن تحديد أو رسم هذا المركز يجعل الطاقة تختفى من التشكيل وذلك لاتجاه الطاقة الى المركز أدق بداخل هذه النقطة التى تم تحديدها وتظل هذه

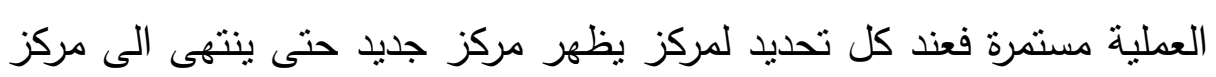

$$
\begin{aligned}
& \text { واحد وهو الله مركز كل شىء } 28 .
\end{aligned}
$$

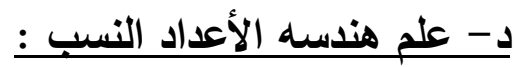

وقد لاحظ كثير من المدققين والباحثين وجود نسب حسابية ثابتة تتكرر فى الكون ومنها النسب الميتافيزيقية والتى أطلق عليها النسبة الذهبية والتى وجنى أخذها الانسان ليبدع بها إنتاجه وترتبط هذه النسبة بنوعية طاقة منظمة تماتل ونه

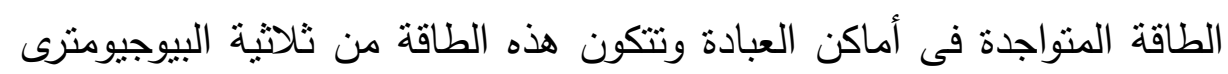
28) محمد سمير الصاوى : "الطاقة ولغة الثكل"، هندسة التشكيل الحيوى بين النظرية والتطبيق، 2015 
(HH-G,HHGOLD,HHUV)

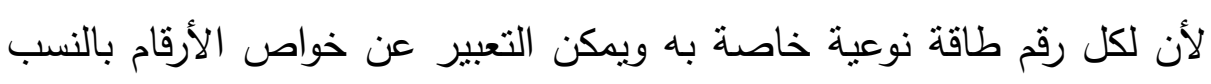
مثل النسبة الذهبية، وبالنالى إذا كانت العين ترى فئ في النظام الكونى الاتزان

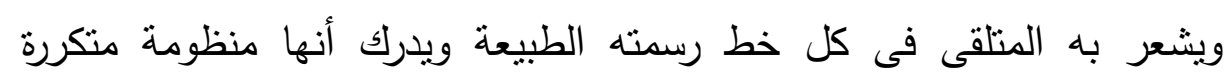

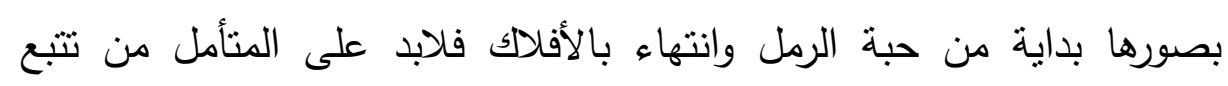

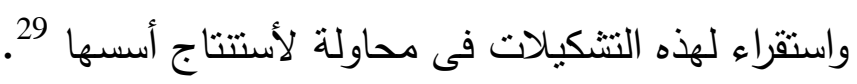

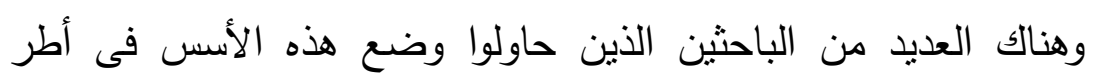

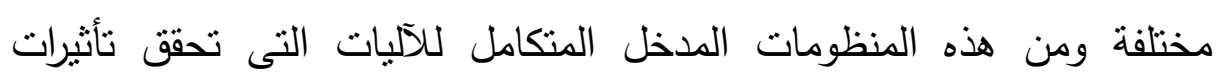

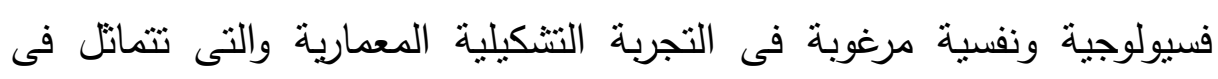

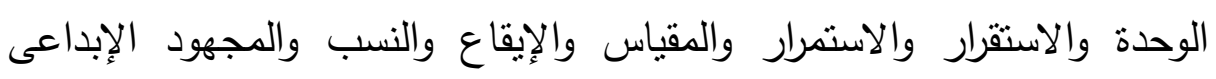
والحقيقة والصورة الذهنية الانترار والانترار ويمكن إيجاد علاقة الرنين ما بين نوعية الطاقة اللطيفة المتتاغمة

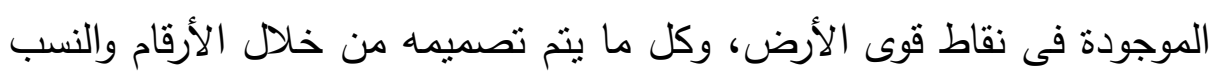

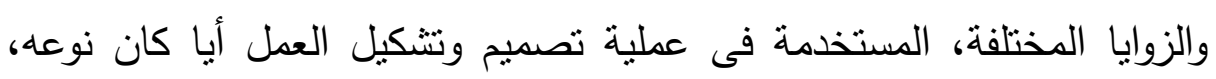

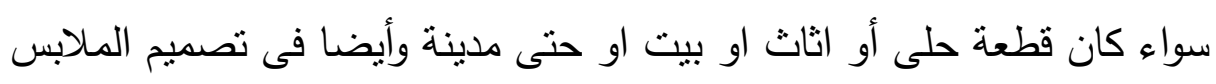

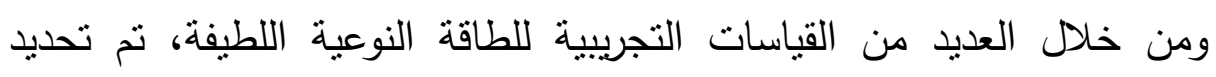
مجموعة من الأرقام تنتاغم مع هذه الطاقة المنظمة التى تتتج ويذكر "د.ابراهيم كريم " أن الرقم (16) هو أول رقم يظهر نوعية الطاقة الطئة

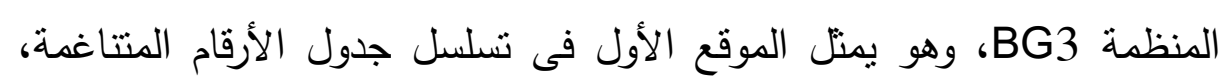
وأن بإيجاد علاقة بين الرقم (16) والرقم (7) داخل حيز التصميم، يعمل على الألى لئل

29) Karim, Ibrahim. (1999).Ancient Egypt and Pythagoras.Bilthoven, Netherlands:Jachtlaan. على رأفت :"الإباع الفنى فى العماره"، الجيزة، مركز أبحاث إنتركونسلت، 1997 . 


\section{المجـلة العلمـية للتربيـة النوعيـة والعلوم التطبيقـية}

\section{The Scientific Journal of Specific Education and Applied Sciences}

إزالة نوعية الطاقة السلبية الصادرة عن الكهرباء، بينما تعمل العلاقة بين الرقم

(16) ورقم (9)على إزالة نوعية الطاقة السلبية الصادرة عن المياه الجوفية

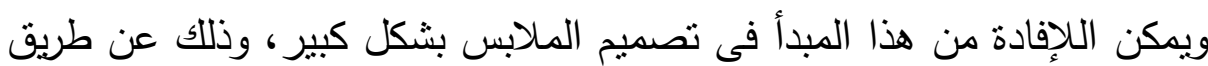
الإفادة من الأرقام الواردة فى جدول التتاغم الرقمى فى تحديد أبعاد التصميم وزواياه وتكرارات عناصره •

\section{BioGeometry Modulor BGM 1-3}

\section{Bast unit 1 fait = 0.1}

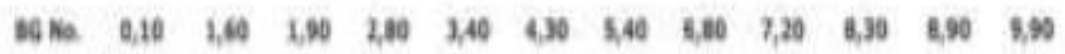

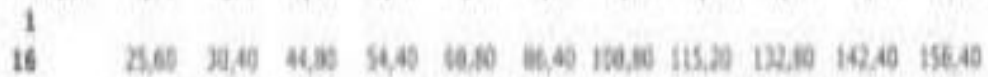

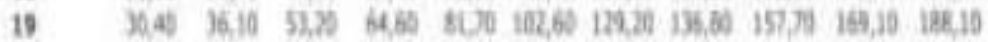

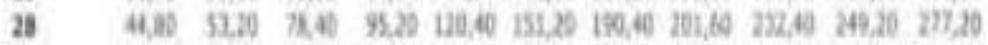

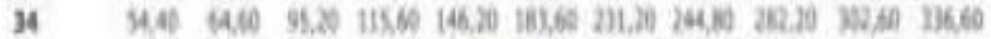

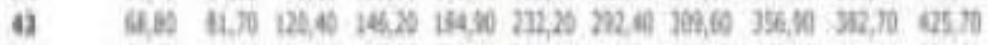

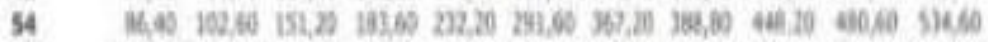

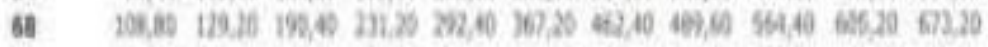

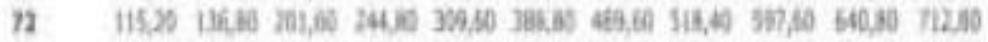

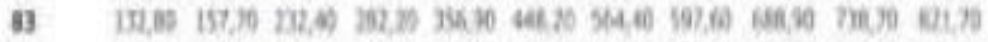

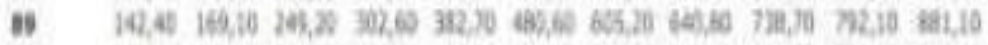

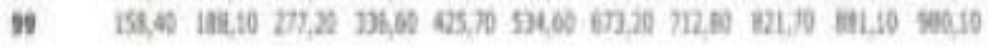

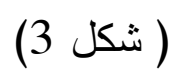

يوضح جدول الأرقام المنتاغمة

$$
\text { ثانيا: بشمل الإطار التطبيقي ما يلحي: }
$$

1- ت تم تصميم (أربعة) تصميمات بلوزات للفتيات من الامام والخلف بتوظيف مجموعه من علوم الطاقه منل العلوم الصينيه والهنديه القديمه وعلم 31) ابر اهيم كريم : محاضرات بشركة بايوجيومثرى كوسيلتنجه، المعادى، فبر اير، 2009 . 
هندسه التشكيل الحيوى وعلم الأعداد والنسب تبعا لاسس وقواعد كل علم من تلك العلوم. -2 نم تصميم (2) استماره استطلاع رأى :

أ ـ استطلاع رأى موجه إلى المتخصصين في مجال الملابس ( ملحق رقم 1): الهرف من استطلاع الرأى التعرف على آراء المتخصصين وقياسها تجاه الناحيه الجماليه للتصميمات المقترحه والتى تم تصميمها تبعا لاسس وقواعد بعض علوم

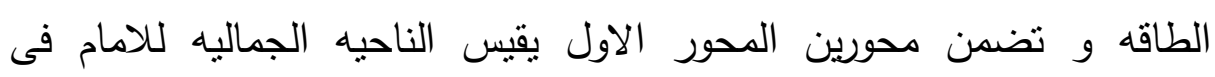
التصميم واشتمل على مجموعة من البنود عددها (11)، والمحور الثانى تتاول

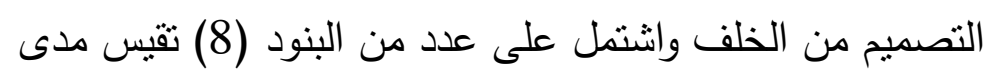

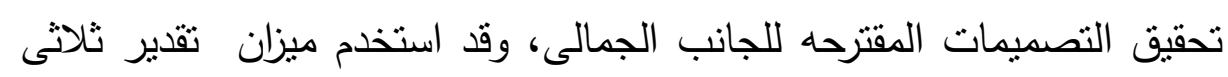

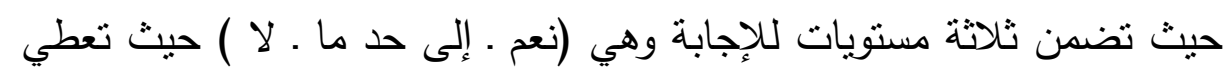

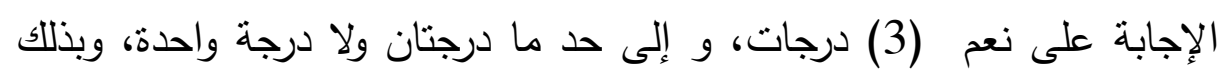

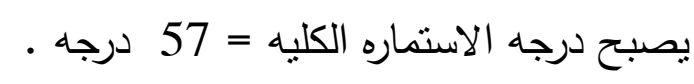

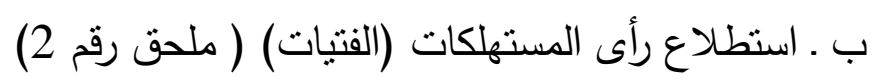

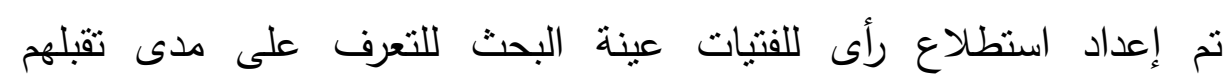
للتصميمات المقترحه، وقد تضمنت الاستماره محورين : المحور الاول تتاول الامام واشتمل على مجموعه من البنود عددها (9) تقيس مدى ملائمتها وتوافقها

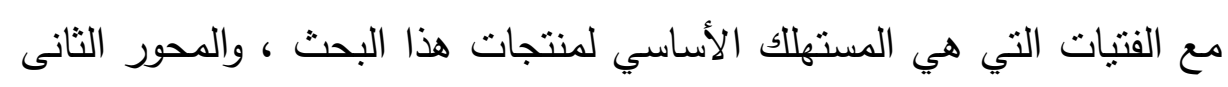
تتاول الخلف واشتمل على عدد (6) بنود ، وقد استخدم ميزان تقدير ثلاثي للاستبيان حيث تضمن ثلاث مستويات للإجابة وهي (نعم · إلى حد ما ل ـ لان)

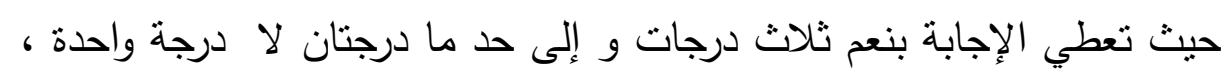
وبذللك تصبح الدرجه الكليه للاستماره =45 درجه. 


$$
\text { صدق وثبات ادوات البحث: }
$$

صدق المحكمين لأستمارتى استطلاع الرأى "الصدق المنطقى" تم عرض

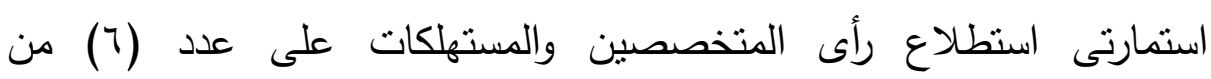
المتخصصين (ملحق رقم 3) ، وذلك بهدف التاكد من دقة الاستمارتين فى لى القياس وفقا للهذف من كل منهما، وقد ابدى المتخصصين بعض الملاحظات وطلبوا بعض التعديلات، وتم التصويب بناء على مقترحاتهم وملاحظاتهم، ، وكانت نسبة اتفاق آراء المحكمون لاستمارة استطلاع اراء المتخصصين 94.25 وبالنسبة لاستمارة استطلاع رأى المستهكات كانت نسبة الاتفاق 93.3 ، وهما نسبتان مرتفعتان تسمح بتطبيق الاستمارتين والوثوق فى رائ نتائجهما.

وفيما يلى عرض الصدق والثبات الاحصائى لأستمارتى استطلاع الرأى: أولاً: استطلاع رأى المتخصصين

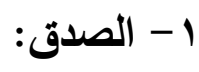

تم حساب الصدق باستخدام الاتساق الداخلي وذللك بحساب معامل إرتباط

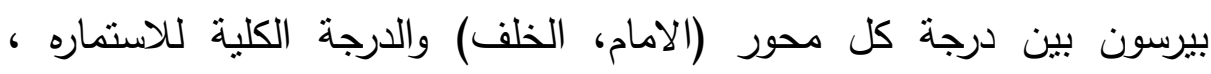
والجدول التالي يبين ذلك:

جدول (1) معاملات الارتباط بين درجة كل محور الدرجة الكلية لاستمارة

\begin{tabular}{|c|c|c|}
\hline 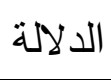 & || الارتباط & المحاور \\
\hline 0.01 & 0.842 & المحور الأول: الامام \\
\hline 0.01 & 0.763 & المحور الثاني: الخلف \\
\hline
\end{tabular}
استطلاع رأى المتخصصين 
يتضح من الجدول أن معاملات الارنباط كلها دالة عند مستوى (0.01) لاقتراب قيم معامل الإرتباط من الواحد الصحيح مما يثير الى صدف استمارة استطلاع رأى المتخصصين وقدرتها على القياس الصحيح وتجانس محاورها.

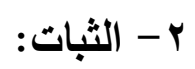

تم حساب الثبات عن طريق معامل "جيوتمان Guttman" بالنسبة للمحاور ولإستبيان ككل، والجدول التالى يبين ذلك:

جدول (2) قيم معامل الثبات لمحاور استمارة استطلاع رأى المتخصصين

\begin{tabular}{|c|c|}
\hline جيوتمان & المعامل \\
\hline 0.812 & ثبات الاستبيان ككل \\
\hline
\end{tabular}

يتضح من الجدول السابق أن قيمة معامل الثبات جيوتمان دال عند مستوى 0.01 مما يؤكد على ثبات استمارة استطلاع رأى المتخصصين ودقة قياسها واتناق عباراتها والثقة فى المعلومات الناتجة عن استجابات المستهكات

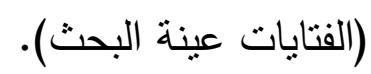
ثانيا: استطلاع رأى المستهركات (الفتيات): 1- الصدق: صدق الاتساق الداخلي :

تم حساب الصدق باستخدام الاتساق الداخلي وذلك بحساب معامل ارتباط

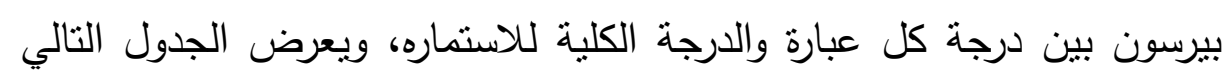

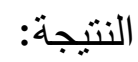


المجـلة العلمـية للتريـــة التوعيـة والعلوم التطبيقية

The Scientific Journal of Specific Education and Applied Sciences

جدول (3) معاملات الارتباط بين درجة كل عبارة والدرجة الكلية للاستبيان

\begin{tabular}{|c|c|c|c|c|c|c|c|c|}
\hline الدلالة & الارتباط & 5 & الد لالة & الارتباط & 5 & الدلالة & الارتباط & م \\
\hline 0.05 & 0.621 & 11 & 0.01 & 0.852 & 6 & 0.01 & 0.931 & 1 \\
\hline 0.05 & 0.610 & 12 & 0.05 & 0.633 & 7 & 0.01 & 0.842 & 2 \\
\hline 0.01 & 0.789 & 13 & 0.01 & 0.876 & 8 & 0.01 & 0.764 & 3 \\
\hline 0.01 & 0.823 & 14 & 0.01 & 0.824 & 9 & 0.05 & 0.612 & 4 \\
\hline 0.01 & 0.773 & 15 & 0.01 & 0.912 & 10 & 0.01 & 0.913 & 5 \\
\hline
\end{tabular}

يتضح من الجدول أن معاملات الارتباط كلها دالة عند مستوى (1 .،. -., •. لاقتراب قيم معامل الارتباط من الواحد الصحيح مما يدل على صدق وتجانس

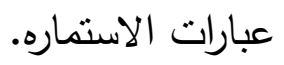

$$
\text { r }
$$

تم حساب الثبات عن طريق معامل الفا كرونباخ Alpha Cronbach جدول (4) قيم معامل الثبات لإستبيان المستهرنكات

\begin{tabular}{|c|c|}
\hline الفا كرونباخ & المعامل \\
\hline 0.878 & قيم الثبات \\
\hline
\end{tabular}

يتضح من الجدول السابق أن قيمة ثبات معامل الفا دالة عند مستوى I +.،

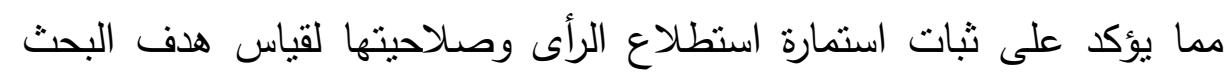
الذى صممت لتحقيقه. نتائج البحث:

الفرض الاول : ينص الفرض الاول على انه "يمكن الاستفادة من دراسة علوم الطاقه في ابتكار تصميمات تتاسب الفتيات فى مرحلة الثباب". 


\section{المجلة العلمـية للتربيـة النوعيـة والعلوم التطبيقـية}

\section{The Scientific Journal of Specific Education and Applied Sciences}

للتحقق من هذا الفرض تم تصميم عدد (4) تصميمات مختلفه كل تصميم مصمح تبعا لاسس وقواعد احد علوم الطاقه الحيويه المختلفه وتم تحليل التصميمات للتأكيد على انه يمكن من خلال عناصر التصميم واسس وقيم علوم الطاقه تحقيق النواحى الجماليه لتصميمات البلوزه للفتيات من سن (18: (30) كالتالى التصميم الاول - علم الهندسه الصينى

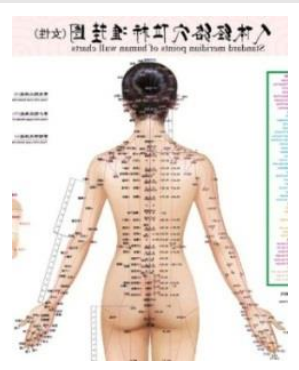

الخلف

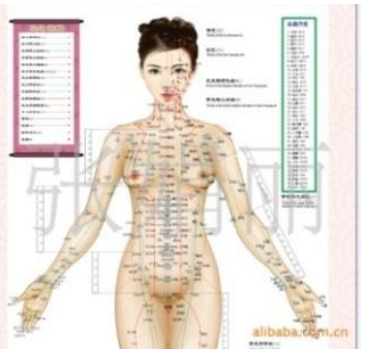

الامام

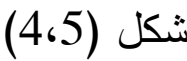

مسارات الطاقه واماكن الابر الصينيه قى جسم المرأه

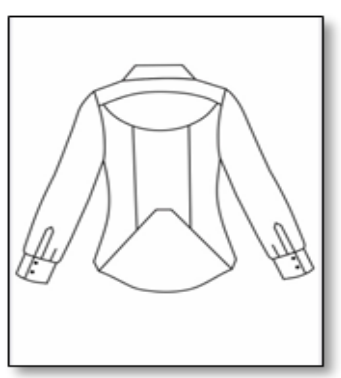

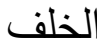

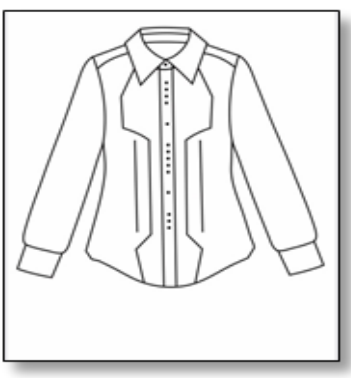

الامام

شكل (6.7)

تصميم بلوزه تبعا لقواعد واسس علم الهندسه الصينى

- استخدمت الدراسه الرنين الثكلى مع مسارات الطاقه الصينيه المرتبطه بجسم الإنسان حيث تم ربط خطوط التصميم بمسار الطاقه عن طريق قصات تمر على تلك 


\section{المجـلة العلمـية للتربيـة النوعيـة والعلوم التطبيقية}

\section{The Scientific Journal of Specific Education and Applied Sciences}

المسارات وبزوايا تتركز على بعض اماكن الابر الصينيه فى الجسم ،كما وضع فى الإعتبار التناسب الهندسى والجمالى •

- التصميم متماتل فى كل من الامام والخلف مما يوحى بالثبات والراحه البصريه. - الامام:تتوع اتجاهات الخطوط فالطوليه المتمتله فى خطى المرد والقصه الموازيه له والتى تؤكد على بعض نقاط الطاقه بالجسم كذلك خطى بنسة الوسط مع الخط العرضى المتمنل فى سفرة الامام وخط الاسوره مع الخطوط المنحنيه فى القصات وخط الذيل كلها مجتمعه تعمل على اعطاء حركه داخل التصميم . - الخلف: تتوع اتجاهات الخطوط فى تصميم الخلف مابين خطوط مستقيمه طوليه ومائله وخطوط منحنيه باتجاهات مختلفه قسم مساحة الحلف الى اشكال هندسيه بنسب متتاسبه . التصميم الثانى - علم الهندسه الهندى

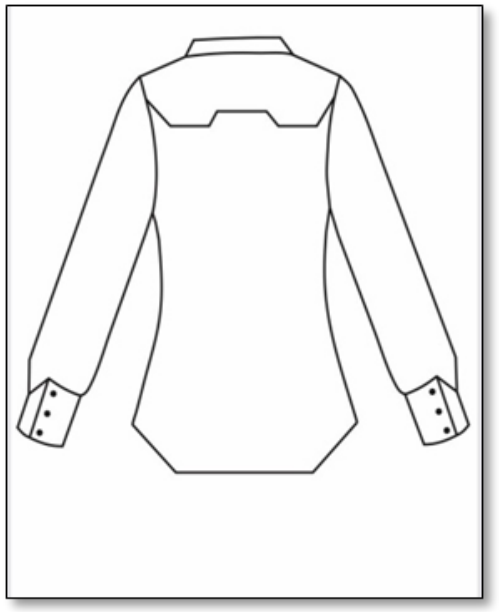

الخلف

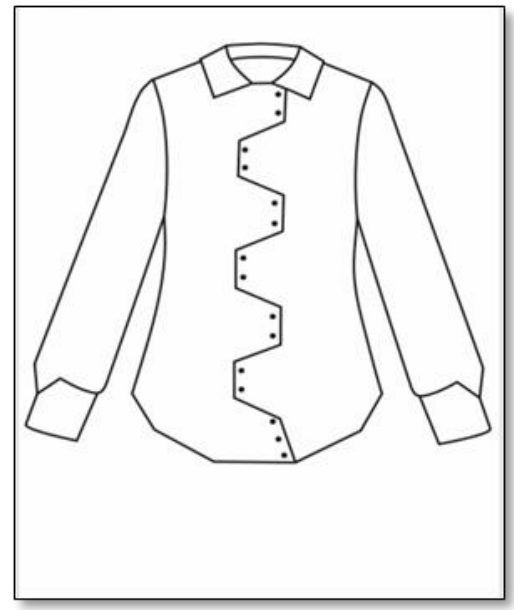

الامام

شكل (8،9)

تصميم بلوزه تبعا لقواعد واسس علم الهندسه الهندى 


\section{المجـلة العلمـية للتربيـة النوعيـة والعلوم التطبيقـية}

- اعتمد التصميم على أماكن الثكرات بالجسم ( صوره 2 ) والتى تعبر فى علم الطاقه الهندى عن مراكز الطاقه السبعه فى جسم الانسان والتى تتمركز فى خط نصف الامام و تتحكم فى طاقة الجسم مع التأكيد عليها وإستخدام الزوايا الهنديه لتنشيط بوابات الطاقه وإستفادة الجسم منها . - التصميم متمانل ممايعطى احساس بالاتزان والثبات . - الامام: خط التصميم الرئيسى مستقيم اتخذ اتجاهات مختلفه وايضا خط الذيل وخط الاسوره مما يعطى الايحاء بالحركه الهادئه فى التصيم ، و تكرار الازرار يؤدى الى الى

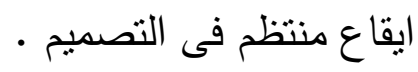
- الخلف: التصميم من خلال خط مستقيم باتجاهات مختلفه وخط الذيل والاسوره يعطى الايحاء بالحركه الهادئه فى التصميم. التصميم الثالث - علم هندسة التشكيل الحيوى (البايوجيومترى )

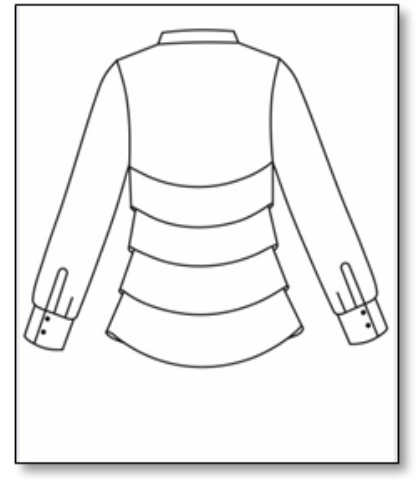

الخفف

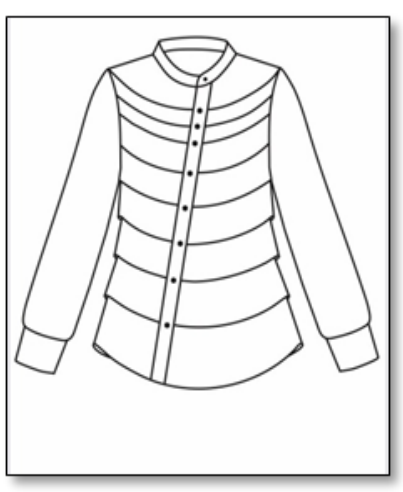

الأمام

شكل (10 ، 11 (11)

تصميم بلوزه تبعا لقواعد واسس علم الهندسه التشكيل الحيوى 


\section{المجـلة العلمـية للتربيـة النوعيـة والعلوم التطبيقية}

المتراكبه ذات المراكز المتعدده وبالتالى هذا التراكب يؤدى الى حركه تثير الى الى المركز وبالتالى تتولد طاقه، مع تطبيق اسس التصميم بالبيوجيومترى ومنها التداخل والثنفافية

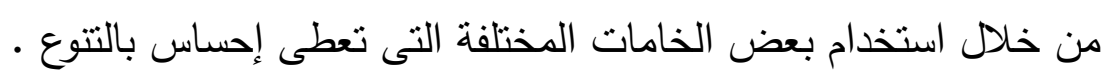

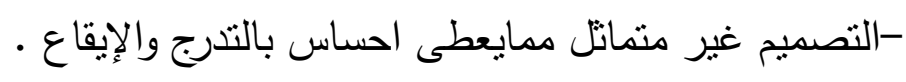

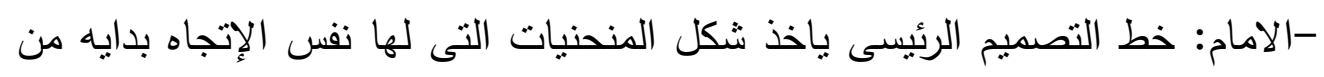

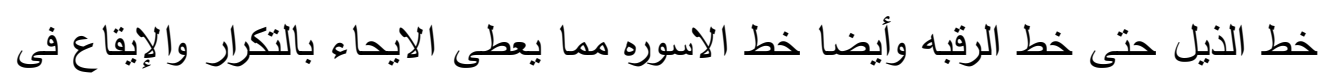

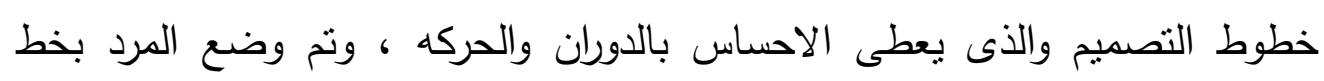

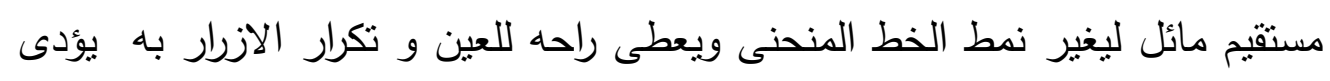

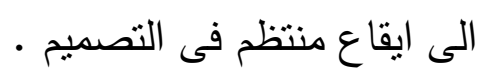

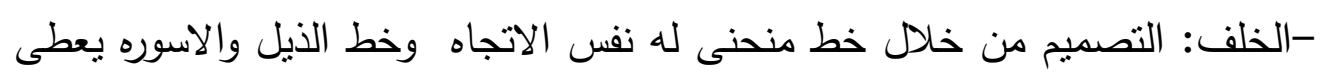
الايحاء بالحركه الهادئه فى التصديم.

التصميم الرابع - علم هنسة الأعداد وإلنسب

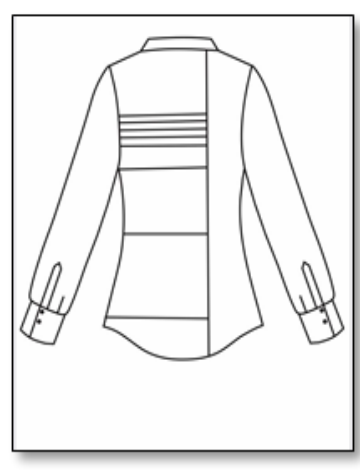

الخلف

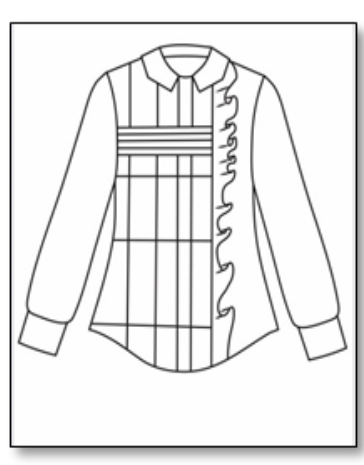

الأمام

شكل(12 ، 13)

تصميم بلوزه تبعا لقواعد واسس علم هندسه الاعداد والنسب 
- تم وضع التصميم بناءا على نتافق النسب الهندسية المرتبطة بعلوم الاعداد والايقاع لها ونتج عن تقاطع تلك الخطوط وزياده عددها وسمكها نكوين شبكه تولد طاقه حركيه ذات بناه اتزان فى التتاسب الهندى الجمالى، مع ادخال الحركة التموجية والتى تعطى احساس • بالسرعة والتغير

- التصميم غير متماتل فى كل من الامام والخلف مما يوحى بالثبات والراحه البصريه.

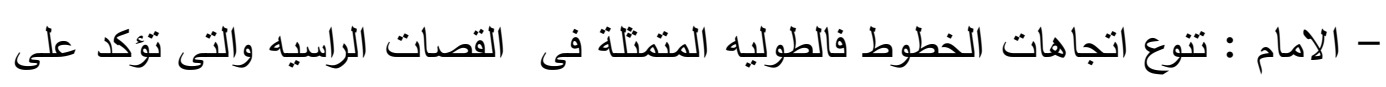
النسبه والتتاسب من خلال المسافات بين الخطوط وذللك على بعض نقاط الطاقه فى الجسم،

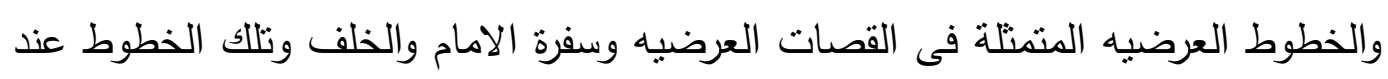
تقاطعها معا تكون شبكه بتتاسب طاقى، وخط الاسوره مع الخطوط المنحنيه فى الذيل

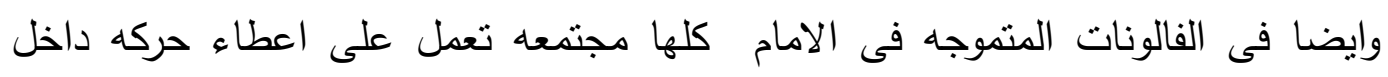
- التصميم - الخلف: تتوع اتجاهات الخطوط فى تصميم الخلف مابين خطوط مستقيمه عرضيه مع خط واحد طولى وخطوط منحنيه فى الذيل قسم مساحة الخلف الى اثكال هندسيه بنسب

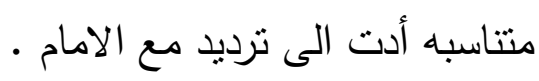
بناء على التصميمات السابقه وتحليلها تبعا لاسس وقواعد علوم الطاقد الطه المختلفه يتحقق

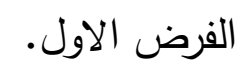

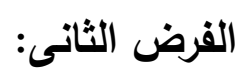

ينص الفرض على أنه "توجد فروق ذات دلالة إحصائية بين التصميمات الاربعه وفقا لآراء المتخصصين للتحقق من هذا الفرض نم إجراء تحليل التباين لارجات التصميمات الاربعه تبعاً لآراء عينة المتخصصين والجدول التالي يبين ذلك: 
المجـلة العلمـية للتريـــة التوعيـة والعلوم التطبيقـية

The Scientific Journal of Specific Education and Applied Sciences

جدول (5) تحليل التباين لارجات التصميمات الاريعه وفقا لآراء المتخصصين

\begin{tabular}{|c|c|c|c|c|c|}
\hline الدلالة & ق فيمة & درجات & المتوسط & مجموع & المتخصصين \\
\hline \multirow{3}{*}{$\begin{array}{r}0.01 \\
\text { دال }\end{array}$} & \multirow{2}{*}{49.857} & 3 & 25994.837 & 77984.511 & بين \\
\hline & & 20 & 521.386 & 10427.72 & داخل \\
\hline & & 23 & & 88412.231 & المجموع \\
\hline
\end{tabular}

يتضح من جدول (6) أن قيمة ( ف) كانت (49.857) وهى قيمة دالة إحصائيا عند مستوى(0.01) ، مما يؤكد على وجود فروق حقيقية بين التصميمات الاربعه وفقا لآراء المتخصصين، ولمعرفة هذه الفروق واتجاه دلالاتها تم تطبيق اختبار LSD للمقارنات المتعددة والجدول التالي يوضح ذللك :

جدول (6) اختبار LSD للمقارنات المتعددة

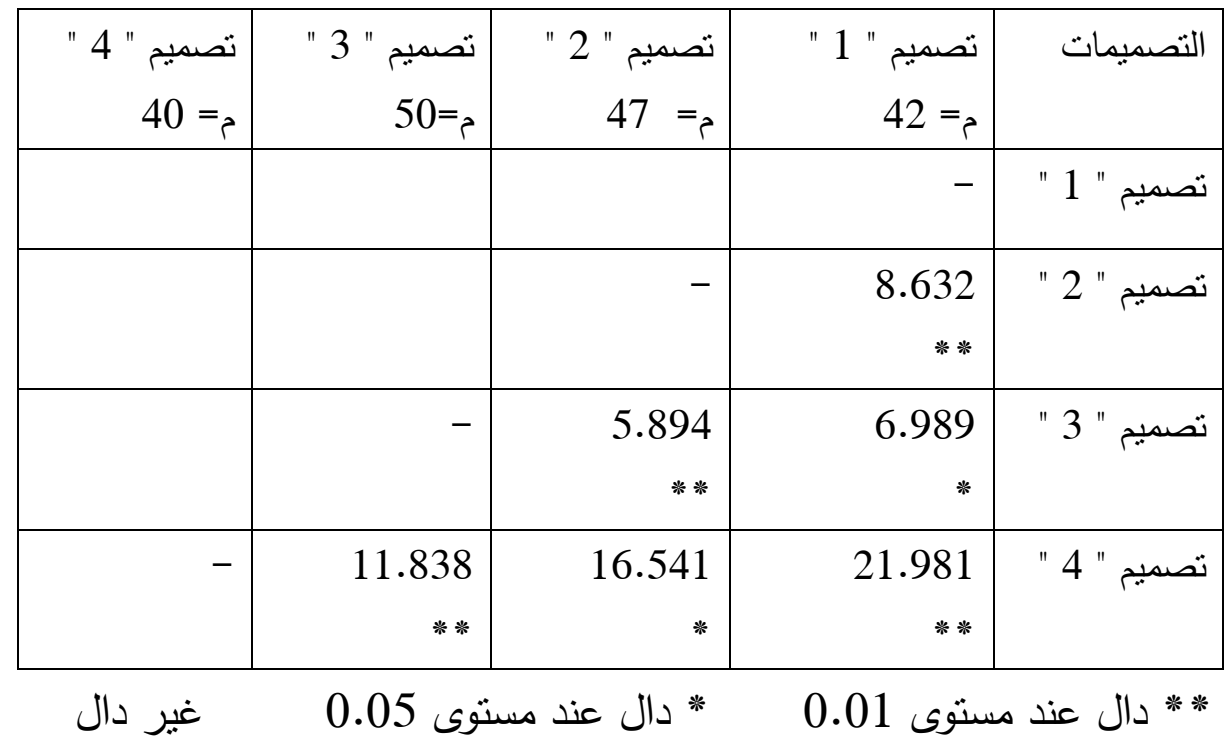


المجـلة العلمـية للتريـــة التوعيـة والعلوم التطبيقية

The Scientific Journal of Specific Education and Applied Sciences

وفيما يلى شكل الأعمدة الأى يبين نتيجة الجدول السابق ويؤكدها.

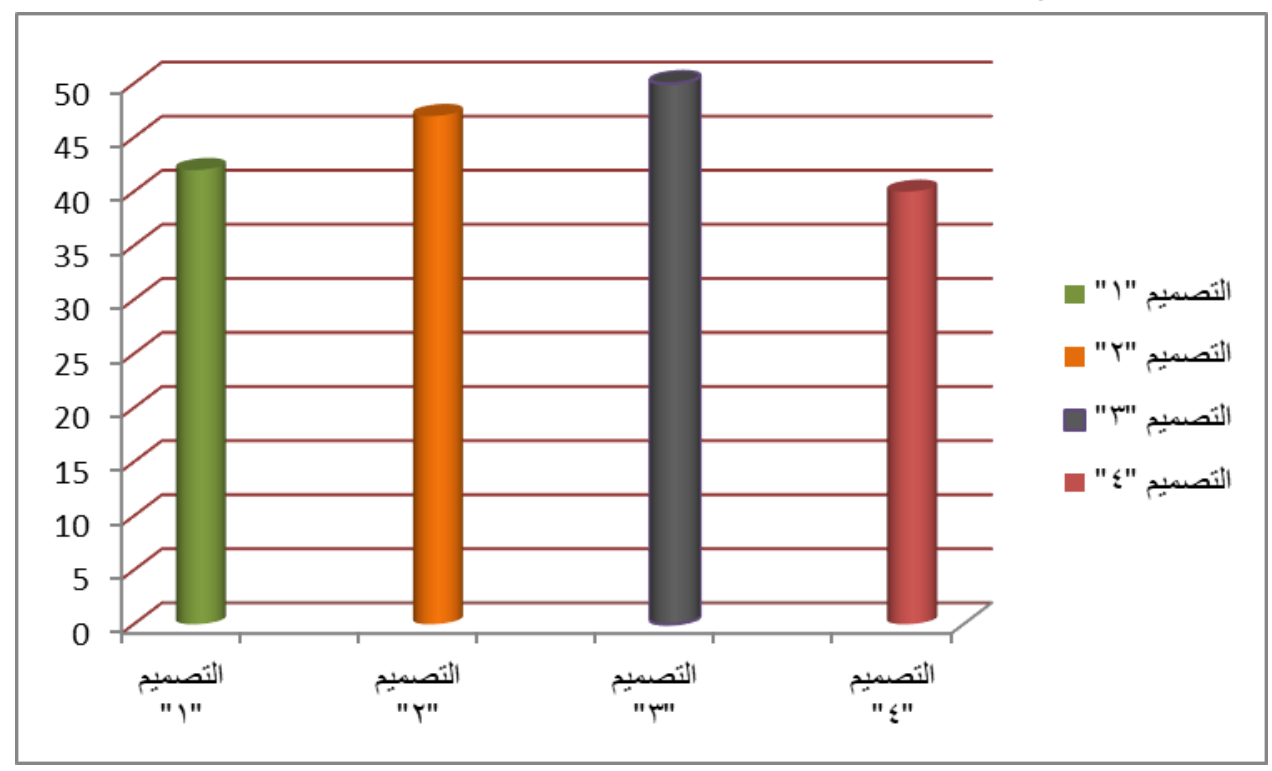

شكل (14) درجات التصميمات الاربعه وفقا للآراء المتخصصين

من الجدول ( 6) والثكل (14) السابقين يتضح ما يلى:

وجود فروق دالة إحصائيا بين التصميمات الاربعه وفقا لأراء المتخصصين عند مستوي دلالة 0.01، 0.05، وبالنظر الى متوسطات درجات تقبيم

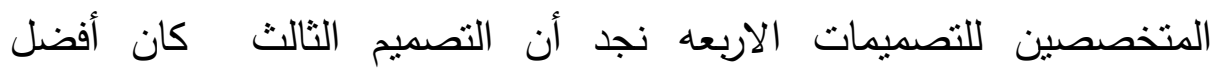
التصميمات وفقا لرأيهم ، يليه التصميم الثانى، ثم التصميم الاول، وأخيرا التصميم الرابع • وبذلك يتحقق الفرض الثانى لرعم الفرض الثالث:

ينص الفرض على أنه "توجد فروق ذات دلالة إحصائية بين التصميمات

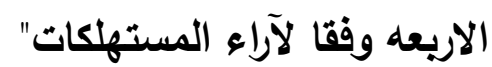
للتحقق من هذا الفرض تم إجراء تحليل التباين لدرجات التصميمات الاربعه تبعاً لآراء المستهلكات (الفتيات) والجدول التالي يبين ذلك: 
المجـلة العلمـية للتريـــة التوعيـة والعلوم التطبيقية

The Scientific Journal of Specific Education and Applied Sciences

جدول (7) تحليل التباين لارجات التصميمات الاريعه وفقا لآراء المستهلكات

\begin{tabular}{|c|c|c|c|c|c|}
\hline الدلالة & قيمة (ف) & الحربة & متوسط & المربعات & المستهلكات \\
\hline \multirow{3}{*}{$\begin{array}{r}0.01 \\
\text { دال }\end{array}$} & \multirow{2}{*}{42.335} & 3 & 16282.192 & 48846.576 & بين \\
\hline & & 396 & 384.599 & $\begin{array}{r}152301.20 \\
4 \\
\end{array}$ & المجل \\
\hline & & 399 & & 201147.78 & المجموع \\
\hline
\end{tabular}

يتضح من جدول (7) أن قيمة ( ف) كانت (42.335) وهى قيمة دالة

إحصائيا عند مستوى (0.01)، مما يؤكد على وجود فروق حقيقية بين

التصميمات الاربعه وفقا لآراء العينه ، ولمعرفة هذه الفروق واتجاه دلالاتها تم

تطبيق اختبار LSD للمقارنات المتعددة والجدول التالي يشير إلى النتيجة:

جدول (8) اختبار LSD للمقارنات المتعددة

\begin{tabular}{|c|c|c|c|c|}
\hline تص=ميم " 42 " & تصميم "39 " " & تصميم " 2 " & تصميم " 1 " & التصميمات \\
\hline & & & - & تصميم " 1 " \\
\hline & & - & 11.692 & تصميح " 2 " \\
\hline & - & 5.894 & 6.989 & تصميم " 3 " \\
\hline & & * * & $*$ & \\
\hline- & 18.288 & 30.060 & 21.981 & تصميم " 4 " \\
\hline & $* *$ & $* *$ & ** & \\
\hline
\end{tabular}

غير دال

0.05 * * دال عند مستوى 0.01 * دال عند مستوى 
المجلة العلمـية للتربيـة النوعيـة والعلوم التطبيقـية

The Scientific Journal of Specific Education and Applied Sciences

وفيما يلى شكل الأعمدة الأى يبين نتيجة الجدول السابق ويؤكدها.

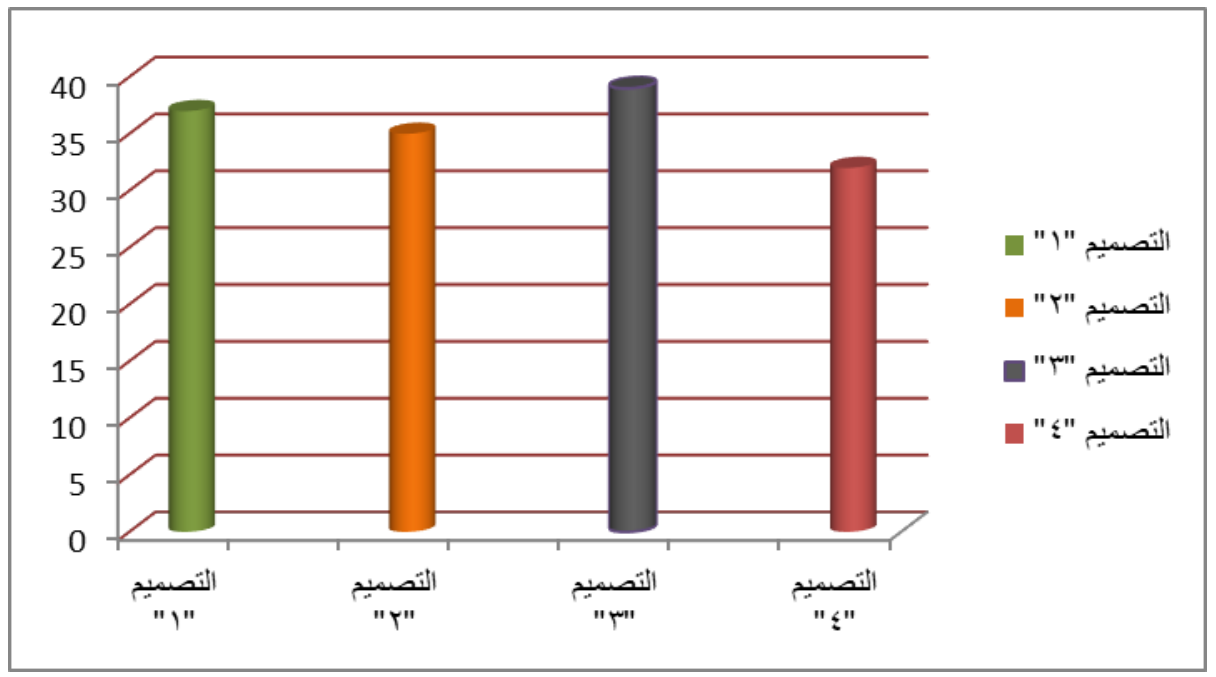

شكل (15) متوسط درجات التصميمات الاربعه وفقا للآراء المستهلكا

من الجدول ( 8) والثكل (15) السابقين يتضح ما يلى:

وجود فروق دالة إحصائيا بين التصميمات الاربعه وفقا لأراء

المستهلكات عند مستوي دلالة 0.01، 0.05 ، ومن خلال درجات منوسطات

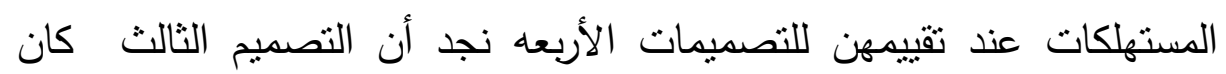

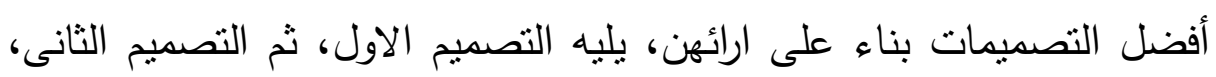

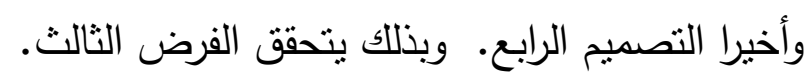

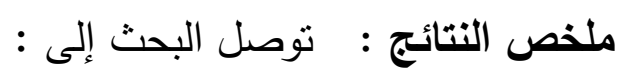
- إمكانيه إنتاج تصميمات ملابس تواكب العصر من خلال التصميم تبعا لأسس البس وقواعد علوم الطاقه مما قد يجعلها تحمل فى طياتها طاقه إيجابيه تساعد الإنسان على أداء الوظائف الحيويه بكفاءه -التصميمات المقترحه والتى تم تصميمها تبعا لاسس وقواعد علوم الطاقه المختلفه قد لاقت قبولا من المتخصصين. 
-هنالك تصميمات اجتمع عليها اراء اغلب المتخصصين انها تحمل قيم جماليه اكثر من غيرها فالتصميم الثالث كان أفضل التصميمات وفقا لرأيهم ، يليه التصميم الثانى، ثم التصميم الاول، وأخيرا التصميم الرابع.

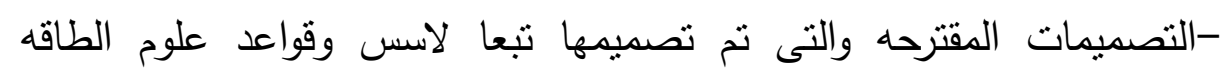
المختلفه قد لاقت قبولا من المستهكئات.

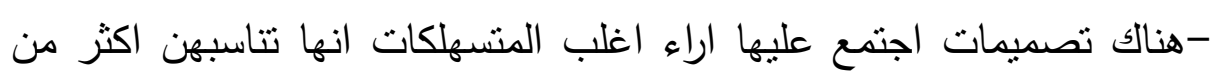
غيرها فالتصميم الثالث الذى تم تصميمه تبعا لاسس وقواعد علم التشكيل الحيوى(البايوجميترى)كان أفضل التصميمات بناء على ارائهن، يليه التصميم الاول الذى تم تصميمه تبعا لاسس وقواعد اسس علم الهندسه الصينى،ثم التصميم الثانى الذى تم تصميمه تبعا لاسس وقواعد علم الهندسه الهندى، وأخيرا التصميم الرابع الذى تم تصميمه بقواعد واسس علم هندسة الاعداد والنسب.

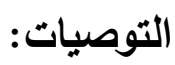
- اجراء دراسات تتناول تطبيق علوم الطاقه فى مجالات الفنون التطبيقيه والتشكيليه المختلفه. - الدعوه لانثاء مراكز بحثيه لعلوم الطاقه من أجل ربط هذة الدراسه

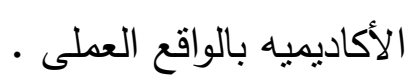
- اقتراح مداخل جديده لتدريس الفنون إعتمادا على فلسفة و نظريات علوم

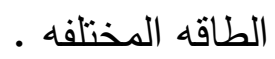
- رفع كفاءة الملابس من خلال تصميمها وانتاجها تبعا لاسس وقواعد علوم الطاقه المختلفه 


\section{المراجع \\ أولا : المراجع العربية:}

1- آلاء أشرف السيد: " اتجاهات حديثة لتصميم الأزياء باستخدام هندسة التشكيل

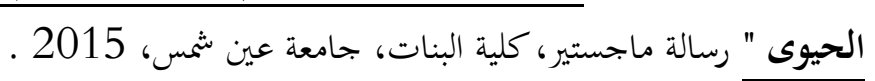

2-

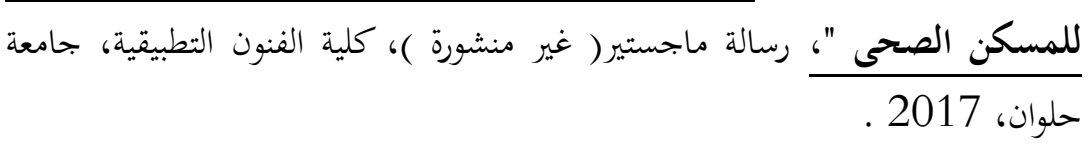

3- ريهام محسن محمد على :" البايوجيومترى كمنهج لصياغة عناصر العمارة والتصميم

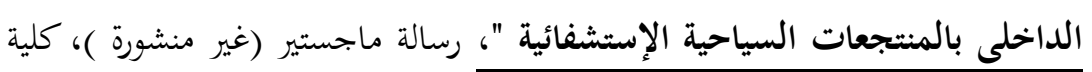

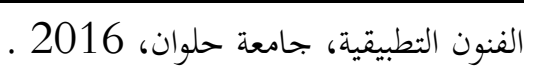

4- سالى إسماعيل عراف :"صياغه مفردات لغه هندسه التشكيل الحيوى فى تصميم

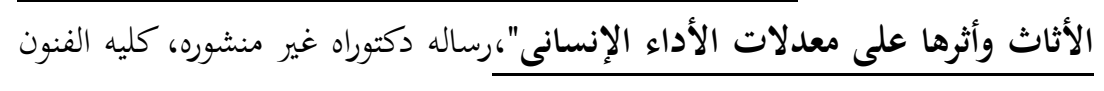
التطبيقيه، جامعه حلوان، 2015 الأناث وائرها على معدلان الأداء الإن

5- سماح عبد العاطى أحمد :"توليف الخامات فى الفن المصرى القديم والإفاده منها

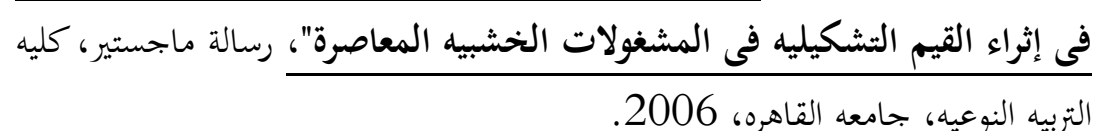

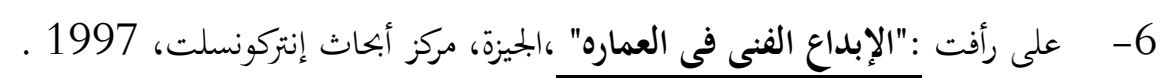

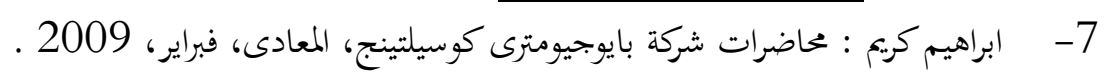
8- - محمد سمير الصاوى :"الطاقة ولغة الشكل"، هندسة التشكيل الحيوى بين النظرية

$$
\text { والتطبيق، دار الهدى، القاهرة ، } 2015 .
$$

9- محمد سمير الصاوى :"العمارة والهندسة الحيوية، نحو منهجية لرفع كفاءة الأداء

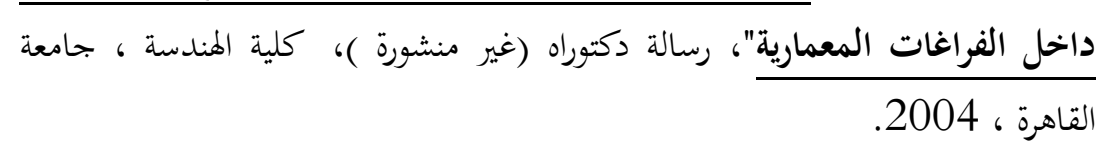

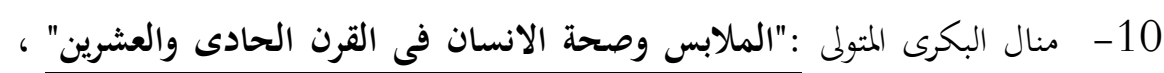

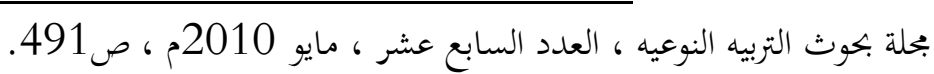


المجـلة العلمـية للتربيــة التوعيـة والعلوم التطبية بـية

The Scientific Journal of Specific Education and Applied Sciences

11- مها محمود إبراهيم :" صياغة جديدة لعناصر التصميم الداخلى من منظورعلوم

الطاقة "، رسالة دكتوراه، كلية الفنون التطبيقية، جامعة حلوان، 2009 .

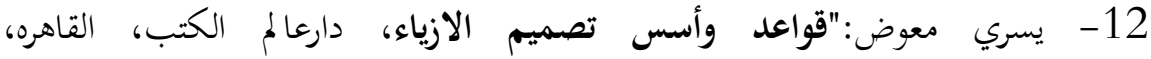

.2،2011b

ثانيا : المراجع الأجنبية:

13- Alvino, Gloria : The Human Energy Field in

Relation to Science, Consciousness, and Health , 1996

,http://www.vxm.com .

14- Cox,Kathleen.(2000).Vastu Living Creating A

Home For The Soul. New York: Marlowe and Company.

15- David, Furlong. (2003). Working With Earth

Energies.London:Judy Piatkus limited.

16- Gerber,Richard.(2000).Vibrational Medicine For

the $21^{\text {st }}$ Century. London: Judy Piatkus Ltd .

17- karim, Ibrahim. (1999).Ancient Egypt and

Pythagoras.Bilthoven, Netherlands:Jachtlaan.

18- Karim,Ibrahim. (2002). Biogeometry and the

Forming Process Back to the Future of New

Architecture. Alexandria:First International Conference of the UIA-WPAHR-V on Architec-ture\&Heritage as a

Paradigm for Knowledge and Development Lessons of the

Past, New Invventions and Future Challenges.

19_ Ibrahem Karim : Back to Future for Mankind, Bio

Geometry Consulting Ltd,Egypt,2009. 
المجـلة العلمـية للتربيــة التوعيـة والعلوم التطبيقـية

The Scientific Journal of Specific Education and Applied Sciences

20- Lubeck, Walter.(2000). Aura Healing Handbook.

Shangri-la,USA:Lotus Press.

21- Radwa Mohamed Fahmy, (2015) INFLUENCE

OF BIOGEOMETRY ON THERMAL COMFORT.

FACULTY OF ENGINEERING, CAIRO UNIVERSITY -GIZA, EGYPT.

22- Sally Essawy, Basil Kamel, Mohamed ElSawy, TIMELESS BUILDINGS AND HUMAN BRAIN The

Effect of Spiritual Spaces on Human Brain Waves, International Journal of Architectural Research

23- Sally Essawy, Basil Kamel, Mohamed Samir. (2014), Sacred Buildings and Brain Performance:The Effect of Sultan Hasan Mosque on Brain Waves of its Users, Chitkara University. All Rights Reserved.

24- Nevin E. Sharaf, Mohamed Samir El-Sawy and Other.(2014). Protective Role of Biogeometry Against Indoor Pollutants of Some Egyptian Building Materials in Adult Male Rats. Misr International University Cairo, Egypt.

$$
\text { ثالثا : مواقع الإنترنت: }
$$

25- https://images.app.goo.gl/yw6phgQT1TU6YJrs9

26-Acupuncturec hart for women http:// ae01.alicdn.com/kf/HTB1xgk m6hSKjiSspn6A79XXaa.jpg?size $=194222 \&$ height $=800 \&$ width $=800 \&$ hash $=725$ af40 https://g.co/kgs/FUjymw 699ce168b973762belee Acupuncture chart for women 27- www.esatclear.ie/cammalot/auraphotos.html 
المجـلة العلمـية للتربيــة التوعيـة والعلوم التطبيقةية

The Scientific Journal of Specific Education and Applied Sciences

\section{Clothing design with energy science methodologies}

\section{Hala Adel Mohammed ELnawawy}

Helwan University - Faculty of Home Economic

\section{Eman Abdelsalam Abdelkade}

Helwan University - Faculty of Home Economic

\section{Mohammed Samir Elsawy}

Misr International University - Faculty of f Engineering

\section{Abstract}

The research aims to put an approach depended on standards and foundations of energy science in clothing design in order to reach designs that achieve the functional, aesthetic and psychological aspect. The research also aims to complete the cycle of designing the clothes with the complementarity between the elements and principles of design, rules and foundations of some energy science in designing ( Chinese and ancient Indian energy science, biogeometry, number and lineage engineering (a clothing product for young people in order to raise the efficiency of their performance The vital, and a number of clothes were designed for young people according to the foundations and rules of energy sciences, by elements and principals of fashion design, then the designs were presented on two samples which were represented in a number(6)of specialists in fashion design to get their views in those designs its aesthetic and functional performance, and(30)young people to know their views on 


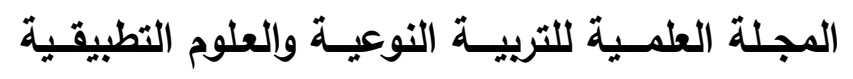

The Scientific Journal of Specific Education and Applied Sciences

them, and the results indicated that the proposed designs have been accepted by both specialists and young people together.

The research approved that-:

-The possibility of producing clothing designs that keep with the times according to the foundations and rules of energy science, which may make it carry a positive energy that helps the human to perform vital functions efficiently .

-The proposed designs which were designed according to the foundations and rules of the energy sciences, have been accepted by specialists.

-There are designs on which the opinions of most specialists have met, that they carry beautiful values more than others. The third design was the best design according to their opinion, followed by the second design, then the first design, and finally the fourth design.

-The proposed designs that were designed according to the different foundations and rules of energy sciences have accepted by consumers 